\title{
ROS Deficiency Exacerbates Donor T Cell-mediated hyperacuteGVHD And Its Predictive Value in Allogeneic HSCT in Human Patients.
}

\section{Yigeng Cao}

Chinese Academy of Medical Sciences and Peking Union Medical College

Jiali Wang

Chinese Academy of Medical Sciences and Peking Union Medical College

Shan Jiang

Chinese Academy of Medical Sciences and Peking Union Medical College

Jiro Sakai

Harvard Medical School Dana-Farber, Harvard Cancer Center, Children's Hospital Boston

Shiyue Zhang

Chinese Academy of Medical Sciences and Peking Union Medical College

Lu Sun

Chinese Academy of Medical Sciences and Peking Union Medical College

Sudong Zhang

Chinese Academy of Medical Sciences and Peking Union Medical College

\section{Tong Wang}

Chinese Academy of Medical Sciences and Peking Union Medical College

\section{Mengnan Lyu}

Chinese Academy of Medical Sciences and Peking Union Medical College

\section{Sizhou Feng}

Chinese Academy of Medical Sciences and Peking Union Medical College

\section{Xiaoming Feng}

Chinese Academy of Medical Sciences and Peking Union Medical College

Hongbo R. Luo

Harvard Medical School Dana-Farber, Harvard Cancer Center, Children's Hospital Boston

Jiaxi Zhou

Chinese Academy of Medical Sciences and Peking Union Medical College

\section{Mingzhe Han}

Chinese Academy of Medical Sciences and Peking Union Medical College

\section{Erlie Jiang}

Chinese Academy of Medical Sciences and Peking Union Medical College

Yuanfu Xu ( $\nabla$ xuyf@ihcams.ac.cn ) 
Chinese Academy of Medical Sciences and Peking Union Medical College

\section{Research Article}

Keywords:

Posted Date: January 28th, 2022

DOI: https://doi.org/10.21203/rs.3.rs-1295930/v1

License: (9) This work is licensed under a Creative Commons Attribution 4.0 International License. Read Full License 


\section{Abstract}

Background: Hyperacute graft-versus-host disease (GVHD) as a severe and lethal disorder frequently occurs within 2 weeks followed by allogeneic haematopoietic stem-cell transplantation (allo-HSCT). Molecular mechanisms underlying allo-HSCT triggered hyperacute GVHD remain elusive.

Method: Using a genetic NADPH-oxidase deficient CGD murine hyperacute GVHD model, we measured the proportion and related function of donor-derived T cells and recipient-derived myeloid derived suppressor cells(MDSC) by flow cytometry. Reactive oxygen species(ROS), a key molecule of immunosuppressive function, was evaluated by luminometer in murine model and cohort patients who received allo-HSCT with or without hyperacute GVHD. We also performed related interventions such as MDSC depletion and ROS agonist to discern the clinical significance of MDSC-NADPH-ROS axis on immune homeostasis. The underlying mechanism on the process of hyperacute GVHD was determined by RNA-sequence assay and cytokine profiling.

Results: Here we surprisedly found that MDSC derived ROS potently prevents hyperacute GVHD by suppressing T cells activation. Moreover, in CGD mice receiving transplantation, the donor derived T cells triggered an immense allo-reactive T cell response and gained killing capacity during hyperacute GVHD. MDSCs, a main cell type for ROS production, exhibited defective suppressive effects on $\mathrm{CD} 8^{+}$and $\mathrm{CD} 4^{+} \mathrm{T}$ cells. Similarly, pharmacological depletion of MDSCs by an anti-Gr1antibody reproduced the hyperacute GVHD phenotype as seen in CGD mice. Conversely, a gain-of-function approach using a ROS agonist prevented development of hyperacute GVHD. Transcriptional analysis showed that T-cell dysregulation during hyperacute GVHD. In a cohort of 17 patients who received allo-HSCT, ROS levels were reversely correlated with hyperacute GVHD development. Together, our data provide novel mechanistic insights into the MDSC-NADPH-ROS suppressive functions in development of allo-HSCT.

Conclusion: On the basis of these findings, we propose a new therapeutic paradigm by delivery of ROS agonists for effective prevention and treatment of hyperacute GVHD.

\section{Background}

Allogeneic hematopoietic stem cell transplantation (allo-HSCT) remains the only potentially curative option for various malignant hematological disorders. Over 1 million hematopoietic cell transplants have been performed worldwide, of which 400000 were allogeneic(1). Hyperacute graft-versus-host disease (GVHD) frequently develops in unprophylaxed or suboptimally prophylaxed recipients with allo-HSCT and confers resistance to first-line therapy. It is a robust and independent predictor of non-relapse mortality(14). Despite this known knowledge, the molecular mechanisms underlying development of hyperacute GVHD are not understood. There is an urgent medical need to prevent and treat the hyperacute GVHD by developing novel effective therapeutics.

Acute GVHD is caused by immune competent T cells in the donated tissue that recognize the recipient as the foreign origin. The activated donor $T$ cells acquire cytolytic capacity to eliminate the foreign antigen 
positive recipient cells. Recipient neutrophils were proved to present allo-antigens to donor $\mathrm{T}$ cells and cause acute GVHD(5). In innate immune responses, neutrophils as the most abundant leucocytes release superoxide radicals and other secondarily-derived reactive oxygen species (ROS). On the other hand, previous studies showed that excessive ROS impairs the function of hematopoietic stem cells (HSCs) and that antioxidants increase engraftment of HSCs in immune-deficient mice $(6,7)$. Given the previous studies showing, we hypothesized that ROS might play a detrimental role in developing hyperacute GVHD. In general, the role of ROS in acute GVHD is vague and comprehensive experimental evidence is require to further strengthen these claims.

In this work, we took a genetic loss-of-function approach to investigate the role of ROS in developing hyperacute GVHD. Surprisingly, all allo-HSCT-transplanted NADPH-oxidase deficient CGD mice experienced sudden death owing to development of hyperacute GVHD. Notably, delivery of a ROS agonist completely rescued these mice from death by preventing hyperacute GVHD. Mechanistically, MDSCderived ROS mediated the suppression of T cell response and transcriptional analysis showed that T-cell dysregulation during hyperacute GVHD. In a limited of human patients, we showed that an overt reverse correlation between ROS levels in the peripheral blood and incidence of hyperacute GVHD. On the basis of these findings, we reasonably propose: 1) ROS levels in the peripheral blood might be used as a surrogate marker for predicting hyperacute GVHD; and 2) ROS agonists could be potentially used for preventing and treating hyperacute and other GVHDs in non-hematopoietic settings.

\section{Materials And Methods}

\section{Human subjects}

Sample collection, and analysis were approved by the Ethics Committee of Blood Diseases Hospital, Chinese Academy of Medical. Written informed consent was obtained from each patient. The patients characteristics, including underlying diagnosis, donor type, conditioning regimen, immunosuppressive regimen, recipient age, and gender, are detailed in Table S1.

\section{Mice and Leukemia cells}

BALB/c $\left(\mathrm{H}-2 \mathrm{~K}^{\mathrm{d}+}\right)$ and $\mathrm{C} 57 \mathrm{BL} / 6$ mice $\left(\mathrm{H}-2 \mathrm{~K}^{\mathrm{b}+}, \mathrm{WT}\right), 8-10 \mathrm{wk}$ of age, were obtained from Chinese Academy of Medical Sciences, and X-linked NOX2-deficient CGD mice (gp91phox-/-, B6.129S6-Cybbtm1Din, H$2 \mathrm{~K}^{\mathrm{b}+}$ ) were kindly provided by professor Hongbo R. Luo (Boston Children's Hospital, Boston, USA). All mice were housed in specific pathogen-free barrier facilities; during procedures animals were kept under laminar flow. Diet consisted of standardized pellet chow and UV decontaminated water. All experiments were approved by the Animal Care and User Committee at the Institute of Hematology, Chinese Academy of Medical Sciences. Plasmid-transduced GFP+ MLL-AF9 leukemia cells $\left({\mathrm{H}-2 \mathrm{~K}^{\mathrm{b}+} \text { eGFP+ }}^{+}\right)$are kindly provided by Dr. Tao Cheng (State Key Laboratory of Experimental Hematology, Tianjin, China) and maintained in liquid nitrogen(8).

\section{Transplantation models}


Gender and age-matching CGD or WT mice that received 9.4 Gy of total body irradiation $\left({ }^{137} \mathrm{Cs}\right.$ source) were intravenously infused with $1 \times 10^{7}$ bone marrow (BM) nucleated cells with co-transfusion of $1 \times 10^{7}$ spleen cells either from allogeneic donors (BALB/c mice) as allo-HSCT, or from syngeneic donors (C57BL/6 mice) as syngeneic hematopoietic stem cell transplantation (syn-HSCT) within 24 hours after irradiation. The day of transplantation was set as day 0.

Lethally irradiated CGD and WT mice that received $1 \times 10^{7} \mathrm{BM}$ nucleated cells from BALB/c mice resuspended in PBS or PBS only at day 0 were defined as the BM and the PBS control group, respectively. Lethally irradiated recipient mice receiving a total of $5 \times 10^{6}$ sorted T cells or T-cell-depleted splenic (TCD$\mathrm{SP}$ ) cells from the spleen of allogeneic donors using anti-CD3 magnetic-activated cell sorting (MACS; Miltenyi Biotec, Auburn, $\mathrm{CA}$ ) at day 0 were defined as the T cell group and the T cell-depleted group, respectively.

\section{GVHD assessment}

The severity of GVHD was assessed with a clinical GVHD scoring system(9). The following 5 clinical parameters were scored: weight loss, posture, activity, fur texture, and skin integrity. At the time of analysis, mice from coded cages were evaluated and graded from 0 to 2 for each criterion. A clinical index was subsequently generated by summation of the five criteria scores (maximum index $=10$ ). Survival was monitored daily.

\section{Histological analyses}

The tissues harvested immediately from recipients at various intervals were placed in 10\% buffered formalin phosphate. The fixed tissues were paraffin embedded, sectioned, and stained with hematoxylin and eosin ((i.e., H\&E). Slides of three main GVHD target tissues (liver, skin, and intestine) were coded without reference to prior treatment and examined in a blinded fashion by three pathologists. The scoring system denoted 0 as normal, 0.5 as focal and rare, 1.0 as focal and mild, 2.0 as diffuse and mild, 3.0 as diffuse and moderate, and 4.0 as diffuse and severe. Scores were added to provide a total score for each specimen $(10,11)$. Lungs ( $n=3$ mice/group) were removed, washed with PBS, fixed in $10 \%$ formalin, and embedded in paraffin. Sections $(5 \mu \mathrm{m})$ were cut and stained with H\&E for light microscopy.

\section{Analysis of bronchoalveolar lavage cells}

WT and CGD mice were sacrificed at day 3 after receiving allo-HSCT. After trachea cannulation, the lungs were lavaged with $1 \mathrm{ml}$ of PBS three times, and the fluids were pooled. Cell counts were performed on all nucleated cells.

\section{Oxidative stress determination}

ROS produced by MDSCs were measured as previously described by us(12).

Briefly, CD $11 \mathrm{~b}^{+} \mathrm{Gr} 1^{+}$cells were sorted from BM cells of normal CGD or WT mice using a BD FACS Aria III 
flow sorter (BD Biosciences, San Jose, CA). The sorted populations were $>95 \%$ pure. Cells were resuspended in PBS with $50 \mu \mathrm{M}$ lunimol and $4 \mathrm{U} / \mathrm{ml}$ horseradish peroxidase (Sigma) with proper $\mathrm{pH}$ value. After stimulation with $1 \mu \mathrm{M}$ fMLP (Sigma), the levels of ROS of $C D 11 b^{+} G R 1^{+}$cells were detected using the luminometer.

ROS accumulation in the BM was measured in freshly isolated BM of recipient mice at day 3 after receiving allo-HSCT using an Amplex Red Hydrogen Peroxide Assay Kit (Invitrogen)(13). Similarly, ROS accumulation in the serum was measured in freshly isolated PB of patients on day 0 before receiving allo-HSCT using the same Kit.

\section{Flow cytometry}

BM cells obtained from flushing ilia, femurs, and tibias and spleen cells of recipients at day 3 after receiving allo-HSCT were stained with antibodies for $40 \mathrm{~min}$ at $4^{\circ} \mathrm{C}$, washed with staining buffer, and analyzed with FACS Cantoll (BD Biosciences, San Jose, CA). Data were analyzed with FlowJo software (Treestar). Hematopoietic reconstitution by the donor-derived cells was monitored by flow cytometry using PE- $\mathrm{H}-2 \mathrm{~K}^{\mathrm{d}}$ and PerCP-Cy $5.5-\mathrm{H}-2 \mathrm{~K}^{\mathrm{b}}$ antibodies. The immunophenotypes of murine LSK (LSKs; $\left.\mathrm{Lin}^{-} \mathrm{CD}^{-} 4^{-} \mathrm{c}-\mathrm{Kit}^{+}\right)$, common myeloid progenitor cells(CMP, CD34+ ${ }^{+} \mathrm{CD} 16 / 32^{\text {int }}$ cells) and megakaryocyte-

erythroid progenitor cell (MEP, CD34 CD16/32 cells)(14) were quantified by the use of APC-c-kit, PE/Cy7lin, FITC-CD34, APC/Cy7-Scar-1 and PE-CD16/32. Meanwhile, APC-Cy7 CD3, FITC- or APC/Cy7-CD4, PE/Cy7-CD8, APC-CD25, PE-CD69, Percp/Cy5.5-CD62L and FITC-CD44 were used for the detection of T cells activation. Antibodies were purchased from Biolegend or ebioscience (San Diego, CA).

\section{Live-cell imaging of cell interactions}

MLL-AF9 leukemia cells -the target cells - were mixed with donor-derived $\left(\mathrm{H}-2 \mathrm{~K}^{\mathrm{d}+}\right) \mathrm{CD}^{+} \mathrm{T}$ cells - the effector cells - isolated from the spleen of CGD or WT mice at day 3 after allo-HSCT at the ratio of 1:1 $\left(1 \times 10^{5} /\right.$ well). The total volume of $400 \mu \mathrm{l}$ cell mixture was inoculated in a 24 -well plate. The pictures were taken every 10 minutes at $37^{\circ} \mathrm{C}$ and $5 \% \mathrm{CO} 2$ using the living cells workstation (Nikon Ti-e, Japan) for 18 hours. Leukemia cells cultured over the same period in the same plates were used as a control. Fluorescence intensity and changes in cell interactions over time were analyzed by FlowJo and Image J software.

\section{Suppression of T cells proliferation}

Recipient derived MDSCs $\left(\mathrm{H}-2 \mathrm{~K}^{\mathrm{b}+} \mathrm{CD} 11 \mathrm{~b}^{+} \mathrm{Gr} 1^{+}\right.$cells) were sorted from BM cells of recipient WT or CGD mice at day 3 after allo-HSCT with a BD FACS Aria III flow sorter (BD Biosciences, San Jose, CA). Splenic $\mathrm{CD}^{+} \mathrm{T}$ cells were obtained from normal $\mathrm{BALB} / \mathrm{c}$ mice using positive bead selection. For cell proliferation detection(15), T cells were incubated at $10^{7} / \mathrm{ml}$ with $2 \mu \mathrm{M}$ carboxyfluorescein succinimidyl ester (CFSE, Invitrogen) for 8 minutes at room temperature and subsequently washed twice in medium with $10 \%$ fetal bovine serum. T cells labeled with CFSE were seeded at $2 \times 10^{5}$ cells/well in 96 well flat-bottom plates (BD 
Falcon) and were stimulated with anti-CD3, anti-CD28 and IL-2 (BD Biosciences) for $72 \mathrm{~h}$ at $37^{\circ} \mathrm{C}$, without or with the addition of MDSCs (at the ratio of 10:1).

\section{In vivo MAb anti-Gr1 antibody and BSO Administration}

Anti-mouse Ly6G/Ly6C antibody (anti-Gr1Ab, 200ug/kg, Bioxcell) was administered intraperitoneally to WT mice 3 hours before and every $48 \mathrm{~h}$ after allo-HSCT $(16,17)$.

Recipient CGD mice of the L-butionine-sulfoxamine (BSO, Sigma-Aldrich) group (BSO group) were injected intraperitoneally with BSO $(10 \mathrm{mg} / \mathrm{kg})$ in PBS 3 hours before and every day after allo-HSCT (13).

\section{RNA-sequencing(RNA-seq) assay}

Recipient derived MDSCs $\left(\mathrm{H}-2 \mathrm{~K}^{\mathrm{b}+} \mathrm{CD} 11 \mathrm{~b}^{+} \mathrm{Gr} 1^{+}\right.$cells) from BM and donor derived T cells $\left(\mathrm{H}-2 \mathrm{~K}^{\mathrm{d}+} \mathrm{CD} 3^{+}\right)$ from spleen of WT or CGD mice at day 3 after allo-HSCT were separated and total RNA were extracted. The RNA-sequencing assay was carried out under using the BGIseq500 platform (BGI, Wuhan,China) and the result data was analyzed by following the manufacturers' protocol.

\section{Cytokine Profiling}

Serum samples of recipient WT and CGD mice with or without BSO treatment were collected from at least 3 mice per group at day 3 after allo-HSCT transplantation. According to the manufacturer's instructions, 17 cytokines associated with T cells were analyzed with a ProcartaPlex Immunoassay Kits (ebioscience, San Diego, CA). The levels of mouse cytokine were examined and reported in units of $\mathrm{pg} / \mathrm{mL}$.

\section{Statistical Analysis}

SPSS software (version 16.0) and GraphPad Prism 5.0 (San Diego, CA) were used to analyze the results and create graphs. All comparisons represent 2-tailed unpaired t-test analyses. P-values $<0.05$ were considered statistically significant. ${ }^{*} P<0.05,{ }^{*} P<0.01$, and ${ }^{* \star *} P<0.001$ were used in comparison.

\section{Results}

\section{Hyperacute GVHD occurs in ROS deficient mice after allogeneic transplantation.}

ROS were crucial for human hematopoietic regulation and antioxidants were able to increase engraftment of HSCs in immune-deficient mice(6, 7). However, lower level of ROS could be more beneficial for allo-HSCT remains unknown, let alone ROS production deficiency.

To investigate the underlying mechanism of ROS in allo-HSCT, the NOX2-deficient mice (i.e., the CGD mice) were established on complete the major histocompatibility antigen (MHC)-mismatch GVHD model (Figure 1A). Surprisingly, the mice with ROS production deficiency - the CGD mice - died rapidly after receiving allo-HSCT, with a median survival time of 4 days (range, 3 to 5 days) versus 25 days (range, 22 to 28 days) for WT mice (Figure 1B). The CGD mice exhibited a complication similar to but somewhat 
distinct from typical aGVHD at day 3 including severe ruffling, lack of movement (unless stimulated), slight hunching and skin integration (Figure S1). Compared with WT mice receiving allo-HSCT, CGD mice exhibited continuous weight loss without a great rising tendency of GVHD scores (Figure 1C-D). The white blood cell count of CGD mice with allo-HSCT persisted at less than $1.0 \times 10^{9} / \mathrm{L}$ until the mice died and exhibited the lack of neutrophil repopulation, while that of WT mice recovered after day 8 (Figure 1E). Histological scoring analysis revealed different patterns of impairment in the liver, intestine and skin, which are classic target tissues of aGVHD (Figure 1F). The samples from WT mice showed clear symptoms of aGVHD on day 25 , such as lymphocyte infiltration and hydropic degeneration. In contrast, CGD and WT mice at day 3 had nearly negative clear sign in target tissues (Figure1G-I).

In consideration of the lethally and rapidly progressive complications that CGD mice suffered from and depended only on allogeneic cells infusion, we turned our attention to the hyperacute GVHD phenotype. Based on hyperacute GVHD of humans characterized by unexplained fevers, diarrhea, skin rashes and hepatic toxicity that occur before engraftment (less than 14 days) in patients with allo-HSCT and its distinction from typical aGVHD (12), we defined hyperacute GVHD of mice using the following criteria. The symptoms occurred within 7 days after allogeneic transplantation before engraftment; the mice showed continuous weight loss with irradiation, poor grooming and impaired movement with or without hunching or skin integrated; and the animals died within 2 days after onset of symptoms and atypical histological changes of classical target organs.

\section{The link between low ROS level and the development of hyperacute GVHD symptoms in patients after allo-HSCT.}

To investigate the role of ROS in hyperacute GVHD of patients, we measured the level of ROS in the peripheral blood of 17 patients (Table 1) on the day of allo-HSCT, before the donor stem cells were infused (Figure 2A). These patients were followed up. Although none of the patients died of hyperacute GVHD at the early stage after allo-HSCT because the usage of prophylaxed immunosuppressants, 6 patients developed hyperacute GVHD symptoms, including 6 had unexplained fever, 3 developed diarrhea and 1 developed liver dysfunction seven days after transplantation. The level of ROS of these 6 patients was significantly lower than that of patients without hyperacute GVHD symptoms (Figure 2B). 5year overall survival of patients with and without hyperacute GVHD symptoms was $50.0 \%$ and $90.9 \%$, respectively $(P=0.052$, Figure $2 C)$. We further tested different cytokines of serum from each group. The level of IL-2R of patients with hyperacute GVHD symptoms were significantly higher than of patients without hyperacute GVHD symptoms on the day of allo-HSCT.

These findings, although being limited by the small number of patients, demonstrate that recipients with low ROS level before transplantation are more likely to have hyperacute GVHD symptoms after transplantation and suggest that a moderate level of ROS might be essential for patient receiving alloHSCT. 
Table 1 The relationship between the level of ROS and the development of hyperacute GVHD in patients receiving allo-HSCT.

\begin{tabular}{llllll} 
Patient & $\begin{array}{l}\text { ROS in PB } \\
\text { (unit) }\end{array}$ & $\begin{array}{l}\text { Unexplained } \\
\text { fevers }\end{array}$ & Diarrhea & $\begin{array}{l}\text { Skin } \\
\text { rashes }\end{array}$ & $\begin{array}{l}\text { Hepatic } \\
\text { toxicity }\end{array}$ \\
\hline Case 1 & 45.4 & Yes & No & No & No \\
\hline Case 2 & 51.2 & Yes & Yes & No & Yes \\
\hline Case 3 & 52.5 & Yes & Yes & No & No \\
\hline Case 4 & 53.3 & Yes & Yes & No & No \\
\hline Case 5 & 54.5 & Yes & No & No & No \\
\hline Case 6 & 85.2 & No & No & No & No \\
\hline Case 7 & 139.6 & No & No & No & No \\
\hline Case 8 & 148.6 & No & No & No & No \\
\hline Case 9 & 157.7 & Yes & No & No & No \\
\hline Case 10 & 174.1 & No & No & No & No \\
\hline Case 11 & 187.5 & No & No & No & No \\
\hline Case 12 & 232.2 & No & No & No & No \\
\hline Case 13 & 268.4 & No & No & No & No \\
\hline Case 15 & 300.8 & No & No & No & No \\
\hline Case 16 & 358.1 & No & No & No & No \\
\hline Case 17 & 399.2 & No & Yes & No & No \\
\hline
\end{tabular}

\section{Donor-derived splenic T cells account for hyperacute GVHD.}

To further explored why ROS production deficiency mice suffered from hyperacute GVHD symptoms after allografting, we analyzed survival of WT and CGD mice by using different types of allogeneic cells sorted from BALB/c mice (Figure 3A). Neither of CGD and WT mice receiving donor BM cells displayed hyperacute GVHD at day 3-5. Nor did they develop aGVHD at day 20-30 after transplantation. Both WT and CGD mice survived at the end of observation (day 40). In contrast, all lethally irradiated mice (CGD or WT) receiving only PBS (PBS control) began to die at about 9 days after transplantation of bone marrow failure, much longer than that of CGD mice suffered from hyperacute GVHD $(P<0.01)$. There was no statistical difference of survival between CGD and WT mice in PBS control group (Figure 3B). The survival time of CGD mice receiving T cells was significantly shorter than that of WT mice with the same treatment (Figure $3 \mathrm{C}, \mathrm{P}<0.001$ ), and the survival time was similar to that of CGD mice receiving allo- 
HSCT (Table S2, P>0.05). On the contrary, the survival time of CGD mice receiving T-cell-depleted cells sorted from donor spleens cell (TCD) transplantation was similar to that of WT mice with the same treatment (Figure 3D, $\mathrm{P}>0.05$ ), but was significantly longer than that of CGD mice receiving allo-HSCT (Table S2, p=0.0092).

In order to evaluate the role of donor-derived HSCs and hematopoietic progenitor cells (HPCs) in hyperacute GVHD, we sacrificed CGD and WT mice at day 3 after they received allo-HSCT. As shown in Figure S2, the frequencies and absolute numbers of HSCs and HPCs failed to recover during hyperacute GVHD occurrence, indicating that the fatal complication only depended on the cells infused during transplantation.

Together, these results indicate that the donor spleen-derived T cells are crucial for the hyperacute GVHD phenotype of CGD mice after receiving allo-HSCT.

\section{Elevated activity of allo-reactive T cells during hyperacute GVHD.}

It is widely accepted that GVHD is related to reactivity of donor T cells against host antigens(2). In our study, the spleen of CGD mice sacrificed at day 3 after receiving allo-HSCT was statistically larger, heavier and contained more cells than the WT mice (Figure 4A), indicating that the allo-reactive T cells might be activated and proliferate in immune organs during hyperacute GVHD.

To test this hypothesis, we sacrificed recipient CGD mice suffering hyperacute GVHD at day 3 after alloHSCT and used flow cytometry to analyze cell sizes (increased in activated T cells) and expression of T cell markers CD25, CD44, CD69 (highly expressed in activated T cells) and CD62L (lowly expressed in activated T cells)(18).

We found that during hyperacute GVHD, the proportion and absolute number of $\mathrm{H}-2 \mathrm{Kd}^{+} \mathrm{CD} 3^{+} \mathrm{CD} 8^{+} \mathrm{T}$ cells in both the bone marrow and spleen of CGD mice were significantly higher than those of WT mice (Figure $4 \mathrm{~B})$. In addition, the number of activated $\mathrm{CD} 8^{+} \mathrm{T}$ cells $\left(\mathrm{CD} 62^{-} \mathrm{CD} 69^{+}\right)$was significantly higher than that of WT mice. In CGD mice, the change in $\mathrm{H}-2 \mathrm{~K}^{\mathrm{d}+} \mathrm{CD} 4^{+} \mathrm{T}$ was also consistent with that of $\mathrm{H}-2 \mathrm{~K}^{\mathrm{d}+} \mathrm{CD}^{+} \mathrm{CD}^{+} \mathrm{T}$ cells. Moreover, the proportion and absolute number of these cells increased in bone marrow and spleen, and the number of activated $\mathrm{CD} 4^{+} \mathrm{T}$ cells also increased (Figure $4 \mathrm{C}$ ). Moreover, the result of regular $\mathrm{T}$ cells (CD4 ${ }^{+} \mathrm{CD} 25^{+} \mathrm{FOXP} 3^{+} \mathrm{T}$ cells, $\mathrm{T}$ reg cells) in the spleen of WT mice and CGD mice indicated Treg cells were proliferated and activated during hyperacute GVHD (Figure 4D).

Next, we sorted $\mathrm{H}-2 \mathrm{Kd}^{+} \mathrm{CD}^{+} \mathrm{T}$ cells from the spleen of CGD (CGD-T cells group) or WT mice (WT-T cells group) that received allo-HSCT 3 days to measure the killing ability and genome-wide RNA-seq. Then sorted $\mathrm{CD}^{+} \mathrm{T}$ cells were co-cultivated with $\mathrm{H} 2 \mathrm{~K}^{\mathrm{b}+}$ eGFP ${ }^{+} \mathrm{AF} 9$ tumor cells for 18 hours and measured the killing ability of live cells by video-tracing of the cell-cell interactions over time. Rapid disappearance of green-labeled cells, which represented AF9 tumor cells, was seen for the CGD-T group (Video S1), but not for the WT-T group (Video S2). At the end of experimentation, the eGFP ${ }^{+}$tumor cells in the CGD-T group were significantly fewer than those in the WT-T group (Figure $4 \mathrm{~J}$ ). Then, we took advantages of the gene 
ontology (GO) analysis and found that the upregulated expressed genes of $\mathrm{H}-2 \mathrm{~K}^{\mathrm{d}+} \mathrm{CD} 3^{+} \mathrm{CD} 8^{+} \mathrm{T}$ and $\mathrm{H}-$ $2 \mathrm{~K}^{\mathrm{d}+} \mathrm{CD}^{+}{ }^{+} \mathrm{CD} 4^{+} \mathrm{T}$ cells from CGD and WT were principally associated $\mathrm{T}$ cell activation and acute inflammation response. Different from activation of $\mathrm{B}$ cells activation pathway in $\mathrm{CD} 8^{+}$and $\mathrm{CD} 4^{+} \mathrm{T}$ cells sorted from WT mine, positive regulation of $T$ cells activation, myeloid leukocyte migration and acute inflammatory response were upregulated in T cells from CGD (Figure 4 F-G).

\section{MDSCs with impaired ROS production cannot inhibit T cell proliferation and activation.}

NADPH oxidase NOX2 is mainly expressed in myeloid cells, and the gp91 subunit of NADPH oxidase holoenzyme has been deleted in the CGD mice, leading to the defect in ROS production(13). While representing an escape mechanism for immune surveillance in cancer, MDSCs have a beneficial role in transplantation and function by suppressing alloreactive-T cell responses, reducing the occurrence of typical acute GVHD (aGVHD) (9, 19-32). Because allo-reactive T cells are massively activated and proliferate during hyperacute GVHD, we ask whether these changes can be linked to the level of ROS that is produced by MDSCs $\left(\mathrm{CD} 11 \mathrm{~b}^{+} \mathrm{Gr} 1^{+}\right)$.

First, we determined the level of ROS in $\mathrm{CD} 11 \mathrm{~b}^{+} \mathrm{Gr} 1^{+}$cells from the BM during hyperacute GVHD by using a chemiluminescence-based method. Not surprisingly, the ROS production in $\mathrm{CD} 11 \mathrm{~b}^{+} \mathrm{Gr} 1^{+}$cells of the CGD mice was defective and the ROS production in the BM of CGD mice receiving allo-HSCT after 3 days was significantly lower than that of WT mice (Figure S3A-B). Then, we found that during hyperacute GVHD, the proportion and absolute number of MDSCs in both the BM and spleen of CGD mice were significantly higher than those of WT mice and most all cells were coming from recipient mice (Figure 5AC).

We subsequently tested whether the deficiency of ROS production could attenuate the suppressive function of MDSCs. $\mathrm{CD}^{+} \mathrm{T}$ cells sorted from spleen of normal BALB/c mice were cocultured at the ratio of 10:1 with MDSCs isolated from the BM of WT mice (WT-MDSCs group) or of the CGD mice (CGDMDSCs group) at day 3 after allo-HSCT. The cell mixtures with or without stimulating factors were used as positive and negative controls. The WT-MDSCs showed strong suppressive ability toward proliferation of both $\mathrm{CD} 8^{+}$and $\mathrm{CD} 4^{+} \mathrm{T}$ cells based on CFSE labeling, decreased expression of activation CD69 and increased expression of CD62L. In contrast, CGD-MDSCs displayed impaired suppressive effect on the activation and proliferation of both $\mathrm{CD} 8^{+}$and $\mathrm{CD} 4^{+} \mathrm{T}$ cells, with more dividing cells, and marked upregulation of the activity markers (Figure 5 ). Moreover, a larger number of $\mathrm{CD}^{+} \mathrm{T}$ cells could differentiate toward CD8 ${ }^{+} \mathrm{T}$ cells when cocultured with CGD-MDSCs (Figure 5C, G).

To explore the potential molecular mechanism of inability recipient-derived MDSCs during hyperacute GVHD, we further profiled the transcriptome sequencing of recipient-derived CGD-MDSCs and WT-MDSCs isolated from the BM of WT mice or of the CGD mice at day 3 after allo-HSCT. Pathway enrichment analysis using the Kyoto Encyclopedia of Genes and Genomes (KEGG) pathway database and gene set enrichment analysis (GSEA) were performed. As shown in Figure $5 \mathrm{~K}-\mathrm{L}$, regulation of GVHD and allograft rejection were decreased in CGD-MDSC, consistent with the impaired function of CGD-MDSCs displayed 
on the activation and proliferation of T cells during hyperacute GVHD. These results indicated that ROS production might play a critical role in the suppressive effect of MDSCs on T cell proliferation and activation.

\section{WT mice develop hyperacute GVHD with MDSC depletion.}

Having shown that the level of ROS in mice after allogeneic transplantation is critical and that MDSCs with ROS production defect cannot inhibit T cells in vitro, we asked whether the MDSCs in the recipients are essential for preventing hyperacute GVHD. It has been reported that CD11 $\mathrm{b}^{+} \mathrm{Gr} 1^{+}$MDSCs in $\mathrm{BM}$, spleen and blood can be depleted by the use of an anti-Gr1 antibody(17). Accordingly, we injected antiGr1 Ab (200ug/ $/ \mathrm{kg})$ into recipient WT mice 3 hours before and every $48 \mathrm{~h}$ after allo-HSCT, which reportedly induces severe granulopenia in mice for 3 to 4 days(16). Recipient WT mice injected with PBS were used as a control. As shown in Figure S1D, the responses of WT mice with anti-Gr1Ab injection at the early stage after allogenic transplantation (at day 5) were similar to those of the CGD mice suffering from hyperacute GVHD (Figure S1C). WT mice with anti-Gr1Ab died within 2 days after the onset of illness, and significant differences in survival rate between the anti-Gr1Ab and PBS control groups were observed from day 5 onwards (Figure 6B). In mice with anti-Gr1Ab injection, the size, weight and total cell number of spleen were significantly elevated (Figure $6 \mathrm{C}$ ). The percentage and absolute number of donor-derived $\mathrm{CD} 8^{+} \mathrm{T}$ cells and $\mathrm{CD} 4^{+} \mathrm{T}$ cells from BM or spleen of the WT mice after anti-Gr1Ab injection were significantly higher than those of the WT mice with PBS treatment (Figure 6D, F). Moreover, the activity of the donor-derived $C D 8^{+} T$ cells and $C D 4^{+} T$ cells was elevated (Figure $6 \mathrm{E}, \mathrm{G}$ ). Together, these results further suggest that immunosuppressive ROS-producing MDSCs at the early stage of post-transplantation period serve as an important source to suppress the proliferation and activity of $T$ cells to prevent hyperacute GVHD.

\section{ROS agonist rescues the hyperacute GVHD phenotype of CGD mice}

Because of the ROS production in the CGD mice was defective, we asked whether raising the level of ROS could rescue the CGD mice from obtaining the hyperacute GVHD phenotype. After daily intraperitoneal injection of BSO (a GSH biosynthesis inhibitor(13)) from day 0 to day 10, all of the CGD mice with BSO treatment did not show hyperacute GVHD symptoms at day 3-5 after transplantation, and the conditions of the mice were similar to those of the WT mice at the end of experimentation (Figure S1G). None of the CGD mice with BSO died from day 0 to day 10 , and significant difference in survival was seen between BSO-treated CGD mice and those without the treatment (Figure7A-B). Furthermore, BSO treatment caused the size, weight and total cell number of the spleen to significantly reduce, while the number of donorderived $\mathrm{CD} 3^{+} \mathrm{T}$ cells (both $\mathrm{CD} 8^{+} \mathrm{T}$ cells and $\mathrm{CD} 4^{+} \mathrm{T}$ cells) in the $\mathrm{BM}$ and spleen was significantly reduced (Figure 7C). Moreover, the percentage of activated T cells from both BM and spleen of mice after treated with BSO was significantly lower than that of the control group (Figure 7D-G).

Cytokine Release Syndrome and respiratory failure might play a role in the death of hyperacute GVHD. 
To date, the cause of hyperacute GVHD symptoms remains unknown. It has been hypothesized that the inflammatory cytokine storm produced early on after the preparative regimen likely contributes to the manifestations(2). To identify the cytokine(s) that might induce the occurrence of hyperacute GVHD, we sacrificed WT and CGD mice with or without BSO treatment at day 3 after allo-HSCT and analyzed the production of multiple cytokines associated with $\mathrm{T}$ cells using a commercially available ProcartaPlex Immunoassay Kits. Three independent experiments were conducted. As showing in Table S3, we identified cytokines that were up-regulated by more than 3 fold in the serum of CGD mice with hyperacute GVHD when compared with the WT control; they include IL-1ß, IL-2, IL-6, IL-13, IL-27, IFN-y, IL-12p70, GMCSF, TNF-a, IL-17A and IL-18. In contrast, daily injection of BSO into CGD mice caused a significant decrease in the level of the aforementioned cytokines (Figure 8A-B; statistical analyses are shown).

To determine the death of hyperacute GVHD, we delivered WT and CGD mice sacrificed at day 3 after receiving allo-HSCT to histological examinations. Nearly all tissues including heart, liver, intestine, kidney, etc. of CGD mice suffering hyperacute GVHD were generally normal (data did not shown). However, different from the lung of WT mice, the histological results of the tissue of CGD mice showed a large number of inflammatory cells infiltration, pulmonary hemorrhage and congestion, and an increased or retained inflammatory secretion in the bronchia (Figure $8 C$ ). Moreover, total nucleated cell number was increased in bronchoalveolar fluid of CGD mice (Figure 8D).

\section{Discussion}

$\mathrm{CD} 11 \mathrm{~b}^{+} \mathrm{Gr}^{+}$MDSCs inhibit T cells response and contribute to the prevention of severe GVHD development after allo-HSCT $26-28$. These immature myeloid cells release ROS molecules as part of a major mechanism to exert immunosuppressive functions. In our study, using hyperacute GVHD model in which myeloid cells are devoid of ROS expression, we demonstrate that ROS scavenging in MDSCs result in abberant $T$ cell activation and accelerate the process of hyperacute GVHD. This phenotype can be rescued by ROS agonist, which reminded us targeting MDSC-ROS may provide a potential therapeutic strategy to hyperacute GVHD.

Mouse models of GVHD have provided important insights into the pathophysiology of this disease, which have helped to improve the success rate of HSCT in humans. Previous large-scale clinical studies demonstrated that the incidence of hyperacute GVHD after allo-HSCT is around $9 \%$. However, without an available animal model, the cause(s) for this complication remain unclear, none of the following factors including conditioning regimen, multiple chemotherapy regimens prior to transplantation, the source of stem cells, the amount of mononuclear cells, or the amount of $\mathrm{CD} 34^{+}$cells appears to affect the frequency of hyperacute $\operatorname{GVHD}(2,33,34)$. In present study, we pioneering established a stable murine model of hyperacute GVHD based on NOX2-deficient mice and we find, for the first time, that the CGD mice that are deficient in ROS production rapidly die of hyperacute GVHD after receiving completely mismatched allo-HSCT, while the WT mice do not when treated under the same condition. Thus, the occurrence of hyperacute GVHD may be related to the low ROS level in the recipient. It is clear showed from our study of mouse model that the pathophysiology with which GVHD develops distinguishes 
hyperacute from typical acute GVHD. This mouse model might also further prove the basic understanding of the immunological responses involved in hyperacute GVHD pathology, such as antigen recognition and presentation, the immune reconstitution after transplantation.

It is widely accepted that aGVHD results from the attack of allogeneic donor T cells that are activated by donor antigen presenting cells within immune organs on multiple host organs(11). Consistent with this notion, we find that the CGD mice of the BM group, TCD group, syn-HSCT group and PBS control group do not suffer from hyperacute GVHD, while all CGD mice receiving the graft containing allogeneic spleen T cells fail to survive. In addition, we find that, in sharp contrast to those in WT mice, donor-derived alloreactive T cells in CGD mice suffering from hyperacute GVHD become massively activated, proliferate and obtain a stronger killing ability during hyperacute GVHD. It is worth noting that the target cells used for observing the killing ability of allo-reactive T cells are not the somatic cells in CGD mice, but instead are leukemia cells expressing $\mathrm{H}-2 \mathrm{~K}^{\mathrm{b}}$, and allo-reactive $T$ cells nevertheless exhibit strong killing activities toward these cells. It is therefore likely that unlike in typical acute GVHD in which alloreactive $T$ cells have specific cell types to target, these overreacting allo-reactive $T$ cells can "indiscriminately fire" on the tissues of hosts. Thus, we speculate that donor-derived T cells in the CGD mice may obtain a broad spectrum of killing ability, which explains, to some extent, the clinical manifestation that patients with hyperacute GVHD have rapid and progressive multi-systemic and multiorganic damage(34).

It has been shown previously that ROS plays an important role in MDSC-mediated suppression of T cell function. In the absence of ROS production, MDSCs lose the ability to suppress T cell responses $(35,36)$. We find that after stimulation with $\mathrm{fMLP}, \mathrm{CD} 11 \mathrm{~b}^{+} \mathrm{Gr} 1^{+}$cells from the CGD mice, in which the gp91 subunit of NADPH oxidase holoenzyme is deleted, cannot produce large amounts of ROS, in keeping with previously published findings(13). We also find not surprisingly, the $\mathrm{H}-2 \mathrm{~K}^{\mathrm{b}+} \mathrm{CD} 11 \mathrm{~b}^{+} \mathrm{Gr} 1^{+} \mathrm{MDSC}$ of the CGD mice that receive allo-HSCT three days earlier lose their inhibitory activity toward T cells in vivo and in vitro, while intraperitoneal injection of BSO may assist the impaired MDSCs in inhibiting allo-reactive T cells in vivo, and, in turn, rescue the CGD mice from obtaining hyperacute GVHD. Moreover, we identified the population of recipient-derived $\mathrm{CD} 11 \mathrm{~b}^{+} \mathrm{Gr} 1^{+}$MDSCs with suppressive ability in normal WT mice at day 3 after they receive completely matched major histocompatibility antigen transplantation. Our data are consistent with the hypothesis proposed by Billiau et al that CD11 $\mathrm{b}^{+}$myeloid cells represent a population of normally occurring cells that can expand after myeloablation and BM transplantation(18). It has been reported that administration of JAK inhibitors decrease the severity of aGVHD in mice via reducing numbers of mature neutrophils in the mesenteric lymph nodes and their MHC-II expression(5). In our study, when MDSCs in the WT mice are depleted via anti-Gr1 antibody injection, which starts on the day before HCT and continues until day 10 after allo-HSCT, the ability of the mice to suppress T cell-mediated immune response is largely abolished. Consequently, the WT mice develop hyperacute GVHD. We imagine that these host myeloid cells with immunosuppressive ability, albeit in small numbers, play a crucial role, especially, in the early stage of post-transplantation. 
Although the downstream effector of allo-reactive T cells during hyperacute GVHD is poorly understood, our results indicate that the allo-reactive $T$ cells get higher activity and cytokine storm might result from rapid immune activation, similar to the findings from chimeric antigen receptor T-cell therapy(37), leading to respiratory failure and death. It has been reported that hyperacute GVHD is accompanied by increased serum levels of IL-6 (38), which is also up-regulated by 20 -fold in our study. TNF-a, which is also elevated by 19 -fold in our study, and IL-6 can trigger auto-regulation and do so by increasing the gene transcripts of their own and leading to the net effect of an amplified inflammatory response. The inflamatory response, if uncontrolled, can lead to cytokine storm and organ damage(39). In addition, when stimulated by cytokines produced by allo-reactive $T$ cells and directly contacted with their target cells, macrophages, monocytes, dendritic cells and natural killer cells can also be activated to release inflammatory cytokines, contributing directly or indirectly to the inflammatory process.

In addition, our findings point to a potential novel therapeutic strategy for treating hyperacute GVHD. It has been shown previously that patients who develop hyperacute GVHD have a much poorer response to regular therapy, causing the disease to progress severely and rapidly $(2,40)$. In this study, we applied BSO, a GSH biosynthesis inhibitor which could augment intracellular ROS concentrations in the cultured myeloid cells, as a prophylaxis against hyperacute GVHD, which successfully rescues the mice with ROS defects from death. Based on these findings, we envision that close examination of the level of ROS before and immediately after allogeneic transplantation followed by prophylactic treatment may prove to be an effective strategy to reduce hyperacute GVHD-related morbidity and mortality. Furthermore, effective treatment with BSO indicates that there might be ROS production, other than NADPH oxidasemediated, in organisms during hyperacute GVHD, which needs further researches.

Moreover, albeit with a relative small number of patients, demonstrate a link between low ROS level in recipients before transplantation to the development of hyperacute GVHD symptoms such as unexplained fever, diarrhea and liver dysfunction post-transplantation. Thus, an appropriate level of ROS might be essential for preventing the development of hyperacute GVHD after allo-HSCT.

\section{Conclusion}

In summary, by establishing and using a murine model of hyperacute GVHD we show that allo-reactive T cells are massively activated and proliferate as a result of defective ROS production from MDSCs and the inability of MDSCs to inhibit T cell immune reactions. These responses eventually lead to hyperacute GVHD. Our findings provide new insights into the pathogenesis of GVHD and may improve the clinical management of this lethal complication.

\section{Abbreviations}

GVHD: graft versus host disease; allo-HSCT: allogeneic haematopoietic stem-cell transplantation; synHSCT: syngeneic hematopoietic stem cell transplantation; MDSC: myeloid derived suppressor cell; ROS: reactive oxygen species; HSCs: hematopoietic stem cells; TCD-SP: T-cell-depleted splenic; LSK: Lin CD34- 
c-Kit"; CMP: common myeloid progenitor cells; MEP: megakaryocyte-erythroid progenitor cell; BSO: Lbutionine-sulfoxamine; MHC: major histocompatibility antigen; HPCs: hematopoietic progenitor cells; BM: bone marrow; Treg: regulatory T cells; GO: gene ontology; KEGG: Kyoto Encyclopedia of Genes and Genomes; GSEA: gene set enrichment analysis.

\section{Declarations}

\section{Acknowledgements}

Not applicable.

\section{Authors' contributions}

Y.C. develop the concept, performed experiments, analyzed data, and write the manuscript; J.W. performed experiments and analyzed data; S.J. helped mouse surgery experiments and analyzed data; S.Z. and L.S. nurturing CGD mouse and helped mouse surgery experiments; J Sakai, S.Z., M.L. and T.W. helped performing experiments; S.F. helped design experiments; X.F. provided vital reagents and helped plan experiments; H.R.B. provided CGD mouse, designed the study, supervised the experiments, analyze data and manuscript preparation; J.Z. helped design experiments, analyzed data and helped write the manuscript; M.H. and E.J. develop the concept, helped design experiments and analyzed data; Y.X. designed the study, supervised the experiments, analyzed data and helped write the manuscript.

\section{Funding}

Y.C. is supported by the Fundamental Research Funds for the central universities (3332020052). Y.X. is supported by grants from the National Natural Science Foundation of China (81970107) and Chinese Academy of Medical Sciences Innovation Fund for Medical Sciences (2021-I2M-1-017). E.J. is supported by the National Natural Science Foundation of China (81670171).

\section{Availability of data and materials}

The data-sets used and/or analyzed during the current study are available from the corresponding author on reasonable request.

\section{Ethical approval and consent to participate}

The use of the animals for research purposes was approved by the Institutional Animal Care and Use Committee at the Institute of Hematology. The data described including human in this manuscript were approved by our center's Medical Ethics Committee and conducted in accordance with the Helsinki declaration.

\section{Consent for publication}

All authors agree to publish this article. 


\section{Competing interests}

The authors declare that they have no competing interests.

\section{Author details}

${ }^{1}$ State Key Laboratory of Experimental Hematology, National Clinical Research Center for Blood Diseases, Haihe Laboratory of Cell Ecosystem, Institute of Hematology \& Blood Diseases Hospital, Chinese Academy of Medical Sciences \& Peking Union Medical College. ${ }^{2}$ Hematopoietic Stem Cell Transplantation Center, Institute of Hematology and Blood Diseases Hospital, Chinese Academy of Medical Sciences and Peking Union Medical College, Tianjin, China. ${ }^{3}$ Department of Pathology, Harvard Medical School DanaFarber/Harvard Cancer Center and Department of Laboratory Medicine, Children's Hospital Boston, Boston, USA.

\section{References}

1. Gratwohl A, Pasquini MC, Aljurf M, Atsuta Y, Baldomero H, Foeken L, et al. One million haemopoietic stem-cell transplants: a retrospective observational study. The Lancet Haematology. 2015;2(3):e91100.

2. Saliba RM, de Lima M, Giralt S, Andersson B, Khouri IF, Hosing C, et al. Hyperacute GVHD: risk factors, outcomes, and clinical implications. Blood. 2007;109(7):2751-8.

3. Jaiswal SR, Zaman S, Chakrabarti A, Sehrawat A, Bansal S, Gupta M, et al. T cell costimulation blockade for hyperacute steroid refractory graft versus-host disease in children undergoing haploidentical transplantation. Transplant immunology. 2016;39:46-51.

4. Furlan SN, Watkins B, Tkachev V, Cooley S, Panoskaltsis-Mortari A, Betz K, et al. Systems analysis uncovers inflammatory Th/Tc17-driven modules during acute GVHD in monkey and human T cells. Blood. 2016;128(21):2568-79.

5. Martin PJ. Pathogenic neutrophils in acute GVHD. Blood. 2018;131(16):1774-5.

6. Shen $\mathrm{H}, \mathrm{Yu} \mathrm{H}$, Liang $\mathrm{PH}$, Cheng $\mathrm{H}$, XuFeng R, Yuan $\mathrm{Y}$, et al. An acute negative bystander effect of gamma-irradiated recipients on transplanted hematopoietic stem cells. Blood. 2012;119(15):362937.

7. Hu L, Cheng H, Gao Y, Shi M, Liu Y, Hu Z, et al. Antioxidant N-acetyl-L-cysteine increases engraftment of human hematopoietic stem cells in immune-deficient mice. Blood. 2014;124(20):e45-8.

8. Cheng H, Hao S, Liu Y, Pang Y, Ma S, Dong F, et al. Leukemic marrow infiltration reveals a novel role for Egr3 as a potent inhibitor of normal hematopoietic stem cell proliferation. Blood. 2015;126(11):1302-13.

9. Highfill SL, Rodriguez PC, Zhou Q, Goetz CA, Koehn BH, Veenstra R, et al. Bone marrow myeloidderived suppressor cells (MDSCs) inhibit graft-versus-host disease (GVHD) via an arginase-1dependent mechanism that is up-regulated by interleukin-13. Blood. 2010;116(25):5738-47. 
10. van Leeuwen L, Guiffre A, Atkinson K, Rainer SP, Sewell WA. A two-phase pathogenesis of graftversus-host disease in mice. Bone marrow transplantation. 2002;29(2):151-8.

11. Hill GR, Crawford JM, Cooke KR, Brinson YS, Pan L, Ferrara JL. Total body irradiation and acute graftversus-host disease: the role of gastrointestinal damage and inflammatory cytokines. Blood. 1997;90(8):3204-13.

12. Cao S, Liu P, Zhu H, Gong H, Yao J, Sun Y, et al. Extracellular Acidification Acts as a Key Modulator of Neutrophil Apoptosis and Functions. PloS one. 2015;10(9):e0137221.

13. Kwak HJ, Liu P, Bajrami B, Xu Y, Park SY, Nombela-Arrieta C, et al. Myeloid cell-derived reactive oxygen species externally regulate the proliferation of myeloid progenitors in emergency granulopoiesis. Immunity. 2015;42(1):159-71.

14. Lin $Y$, Hu X, Cheng H, Pang Y, Wang L, Zou L, et al. Graft-versus-host disease causes broad suppression of hematopoietic primitive cells and blocks megakaryocyte differentiation in a murine model. Biology of blood and marrow transplantation : journal of the American Society for Blood and Marrow Transplantation. 2014;20(9):1290-300.

15. Hu X, Zhou Y, Dong K, Sun Z, Zhao D, Wang W, et al. Programming of the development of tumorpromoting neutrophils by mesenchymal stromal cells. Cellular physiology and biochemistry: international journal of experimental cellular physiology, biochemistry, and pharmacology. 2014;33(6):1802-14.

16. Czuprynski CJ, Brown JF, Wagner RD, Steinberg H. Administration of antigranulocyte monoclonal antibody RB6-8C5 prevents expression of acquired resistance to Listeria monocytogenes infection in previously immunized mice. Infection and immunity. 1994;62(11):5161-3.

17. Li L, Zhang T, Diao W, Jin F, Shi L, Meng J, et al. Role of Myeloid-Derived Suppressor Cells in Glucocorticoid-Mediated Amelioration of FSGS. Journal of the American Society of Nephrology : JASN. 2015;26(9):2183-97.

18. Billiau AD, Fevery S, Rutgeerts $\mathrm{O}$, Landuyt W, Waer M. Transient expansion of Mac1+Ly6-G+Ly6-C+ early myeloid cells with suppressor activity in spleens of murine radiation marrow chimeras: possible implications for the graft-versus-host and graft-versus-leukemia reactivity of donor lymphocyte infusions. Blood. 2003;102(2):740-8.

19. Messmann JJ, Reisser T, Leithauser F, Lutz MB, Debatin KM, Strauss G. In vitro-generated MDSCs prevent murine GVHD by inducing type $2 \mathrm{~T}$ cells without disabling antitumor cytotoxicity. Blood. 2015;126(9):1138-48.

20. Blazar BR, MacDonald KPA, Hill GR. Immune regulatory cell infusion for graft-versus-host disease prevention and therapy. Blood. 2018;131(24):2651-60.

21. Talmadge JE, Gabrilovich DI. History of myeloid-derived suppressor cells. Nature reviews Cancer. 2013;13(10):739-52.

22. Albeituni SH, Ding C, Yan J. Hampering immune suppressors: therapeutic targeting of myeloidderived suppressor cells in cancer. Cancer J. 2013;19(6):490-501. 
23. Cuenca AG, Delano MJ, Kelly-Scumpia KM, Moreno C, Scumpia PO, Laface DM, et al. A paradoxical role for myeloid-derived suppressor cells in sepsis and trauma. Mol Med. 2011;17(3-4):281-92.

24. Stokes J, Hoffman EA, Molina MS, Eremija J, Larmonier N, Zeng Y, et al. Bendamustine with Total Body Irradiation Limits Murine Graft-versus-Host Disease in Part Through Effects on Myeloid-Derived Suppressor Cells. Biology of blood and marrow transplantation : journal of the American Society for Blood and Marrow Transplantation. 2018.

25. Park HJ, Byun D, Lee AH, Kim JH, Ban YL, Araki M, et al. CD99-dependent expansion of myeloidderived suppressor cells and attenuation of graft-versus-host disease. Molecules and cells. 2012;33(3):259-67.

26. Vendramin A, Gimondi S, Bermema A, Longoni P, Rizzitano S, Corradini P, et al. Graft monocytic myeloid-derived suppressor cell content predicts the risk of acute graft-versus-host disease after allogeneic transplantation of granulocyte colony-stimulating factor-mobilized peripheral blood stem cells. Biology of blood and marrow transplantation : journal of the American Society for Blood and Marrow Transplantation. 2014;20(12):2049-55.

27. Yin J, Wang C, Huang M, Mao X, Zhou J, Zhang Y. Circulating CD14(+) HLA-DR(-/low) myeloidderived suppressor cells in leukemia patients with allogeneic hematopoietic stem cell transplantation: novel clinical potential strategies for the prevention and cellular therapy of graftversus-host disease. Cancer medicine. 2016;5(7):1654-69.

28. Lin $Y$, Wang $B$, Shan W, Tan $Y$, Feng J, Xu L, et al. mTOR inhibitor rapamycin induce polymorphonuclear myeloid-derived suppressor cells mobilization and function in protecting against acute graft-versus-host disease after bone marrow transplantation. Clin Immunol. 2018;187:122-31.

29. Ostrand-Rosenberg S, Sinha P. Myeloid-derived suppressor cells: linking inflammation and cancer. J Immunol. 2009;182(8):4499-506.

30. Gabrilovich DI, Nagaraj S. Myeloid-derived suppressor cells as regulators of the immune system. Nature reviews Immunology. 2009;9(3):162-74.

31. Zhang J, Chen HM, Ma G, Zhou Z, Raulet D, Rivera AL, et al. The mechanistic study behind suppression of GVHD while retaining GVL activities by myeloid-derived suppressor cells. Leukemia. 2019.

32. Nagaraj S, Youn JI, Gabrilovich DI. Reciprocal relationship between myeloid-derived suppressor cells and T cells. J Immunol. 2013;191(1):17-23.

33. Powles RL, Morgenstern GR, Kay HE, McElwain TJ, Clink HM, Dady PJ, et al. Mismatched family donors for bone-marrow transplantation as treatment for acute leukaemia. Lancet. 1983;1(8325):612-5.

34. Powles R, Pedrazzini A, Crofts M, Clink H, Millar J, Bhattia G, et al. Mismatched family bone marrow transplantation. Seminars in hematology. 1984;21(3):182-7.

35. Gabrilovich DI, Ostrand-Rosenberg S, Bronte V. Coordinated regulation of myeloid cells by tumours. Nature reviews Immunology. 2012;12(4):253-68. 
36. Sullivan KM, Deeg HJ, Sanders J, Klosterman A, Amos D, Shulman H, et al. Hyperacute graft-v-host disease in patients not given immunosuppression after allogeneic marrow transplantation. Blood. 1986;67(4):1172-5.

37. Obstfeld AE, Frey NV, Mansfield K, Lacey SF, June CH, Porter DL, et al. Cytokine release syndrome associated with chimeric-antigen receptor T-cell therapy: clinicopathological insights. Blood. 2017;130(23):2569-72.

38. Imamura M, Hashino S, Kobayashi S, Kobayashi H, Tanaka J, Imai K, et al. Hyperacute graft-versushost disease accompanied by increased serum interleukin-6 levels. International journal of hematology. 1994;60(1):85-9.

39. McGuire TR, Bociek GR, Pavletic SZ, Hock L, Lynch J, Schneider J, et al. Organ dysfunction following stem cell transplantation: relationship to plasma cytokine concentrations. Bone marrow transplantation. 2001;28(9):889-93.

40. Kim DH, Sohn SK, Kim JG, Suh JS, Lee KS, Lee KB. Clinical impact of hyperacute graft-versus-host disease on results of allogeneic stem cell transplantation. Bone marrow transplantation. 2004;33(10):1025-30.

\section{Figures}



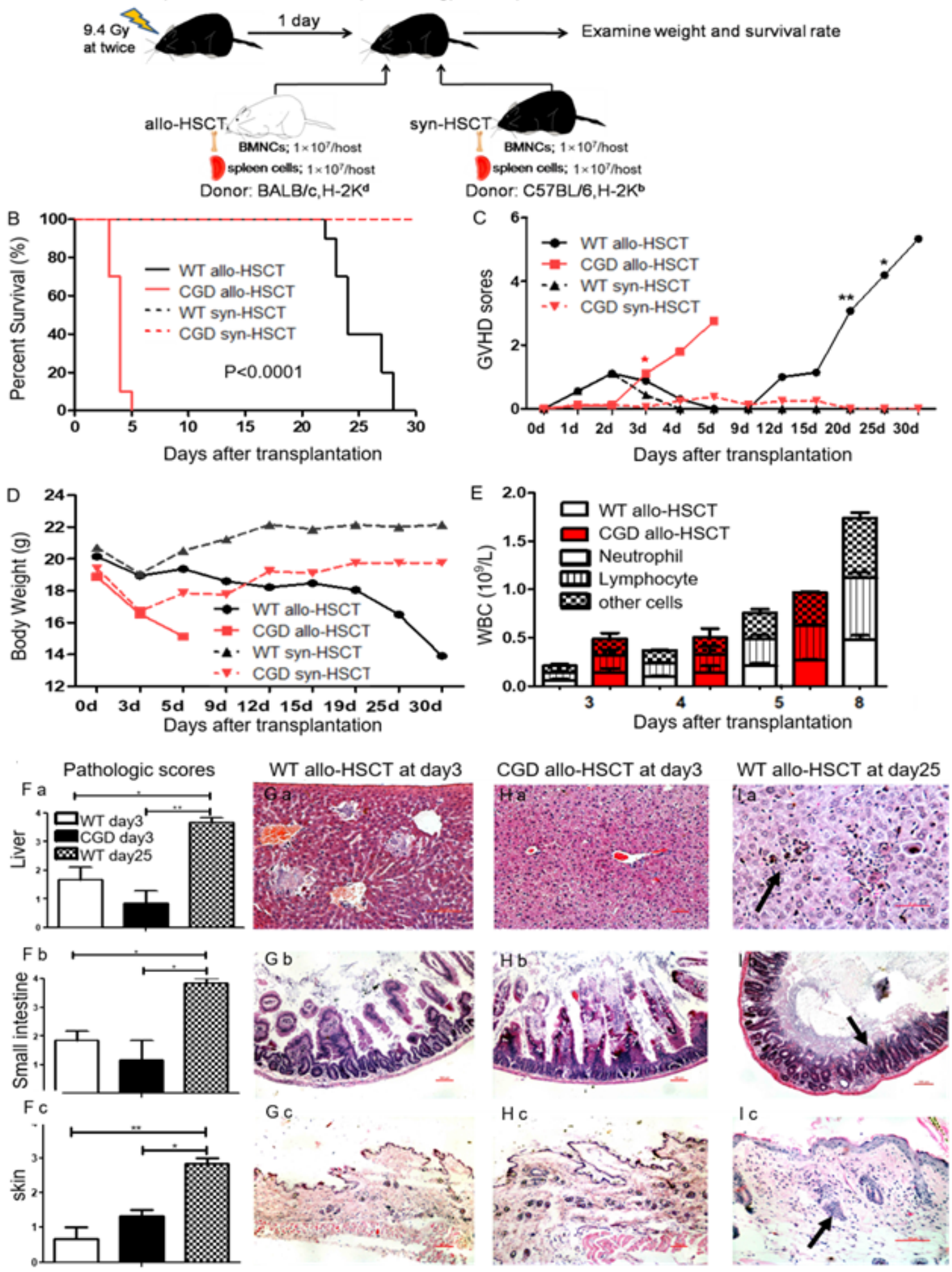

\section{Figure 1}

Hyperacute GVHD occurs in CGD (C57BL/6-gp9 $1^{\text {phox-//) }}$ mice at day 3 after allogeneic transplantation. Schematic representation of the experimental procedure. 9.4 Gy total-body irradiation was used to condition C57BL/6 $\left(\mathrm{H}-2 \mathrm{~K}^{\mathrm{b}}\right)$ or gp91 ${ }^{\text {phox-- }}$ (B6.129S6-Cybbtm1Din, $\left.\mathrm{H}-2 \mathrm{~b}\right)$ chronic granulomatous disease (CGD) mice. Age- and gender-matched BALB/c $\left(\mathrm{H}-2 \mathrm{~K}^{\mathrm{d}}\right)$ or $\mathrm{C} 57 \mathrm{BL} / 6\left(\mathrm{H}-2 \mathrm{~K}^{\mathrm{b}}\right)$ mice were used as donor mice to establish a completely mismatched (allo-HSCT) or completely matched (syn-HSCT) major 
histocompatibility antigen (MHC) murine model (A). CGD mice receiving allo-HSCT had significantly shorter survival than mice in the other three groups based on the Kaplan-Meier analysis (B). Clinical GVHD scores (C) and body weights (D) of CGD and WT mice after allo-HSCT and syn-HSCT. WBC counts in the PB of CGD and WT after allo-HSCT were shown (E). Pathologic scores (F) and histological changes in liver (a), intestine (b) and skin(c) of CGD mice after allo-HSCT at day3 (G); of WT mice after allo-HSCT at day3 $(\mathrm{H})$ and of the WT mice after allo-HSCT at day25 (I) stained with hematoxylin-and-eosin and used for histological scoring of GVHD in a blinded fashion by three pathologists. Data are expressed as mean \pm standard error $(\mathrm{SE}) .{ }^{\star} \mathrm{P}<0.05 ; * \star \mathrm{P}<0.01$. These results are representative of at least 3 independent experiments and greater than 5 mice in each group.

A

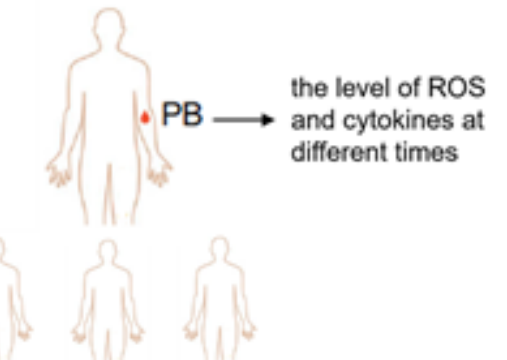

Patients received allo-HSCT $(n=17)$
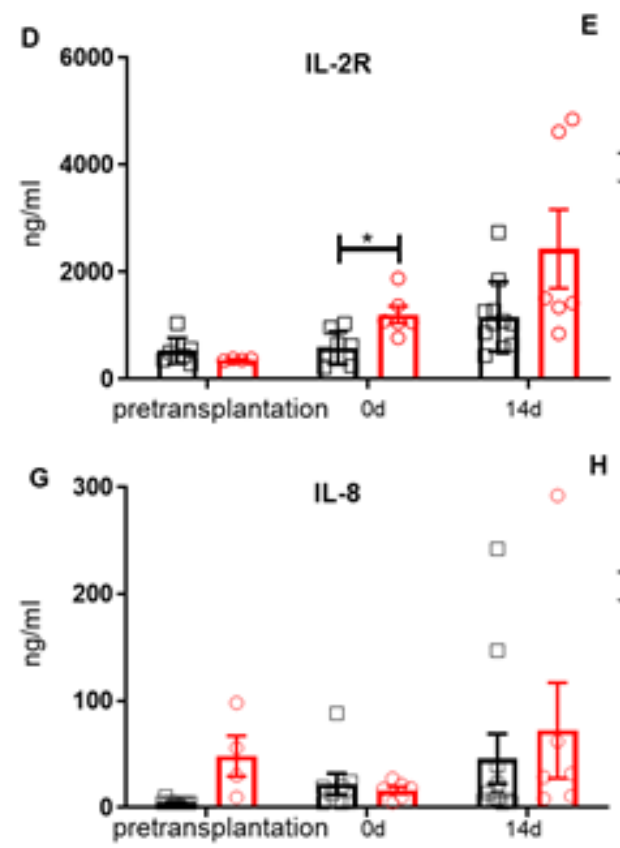

B
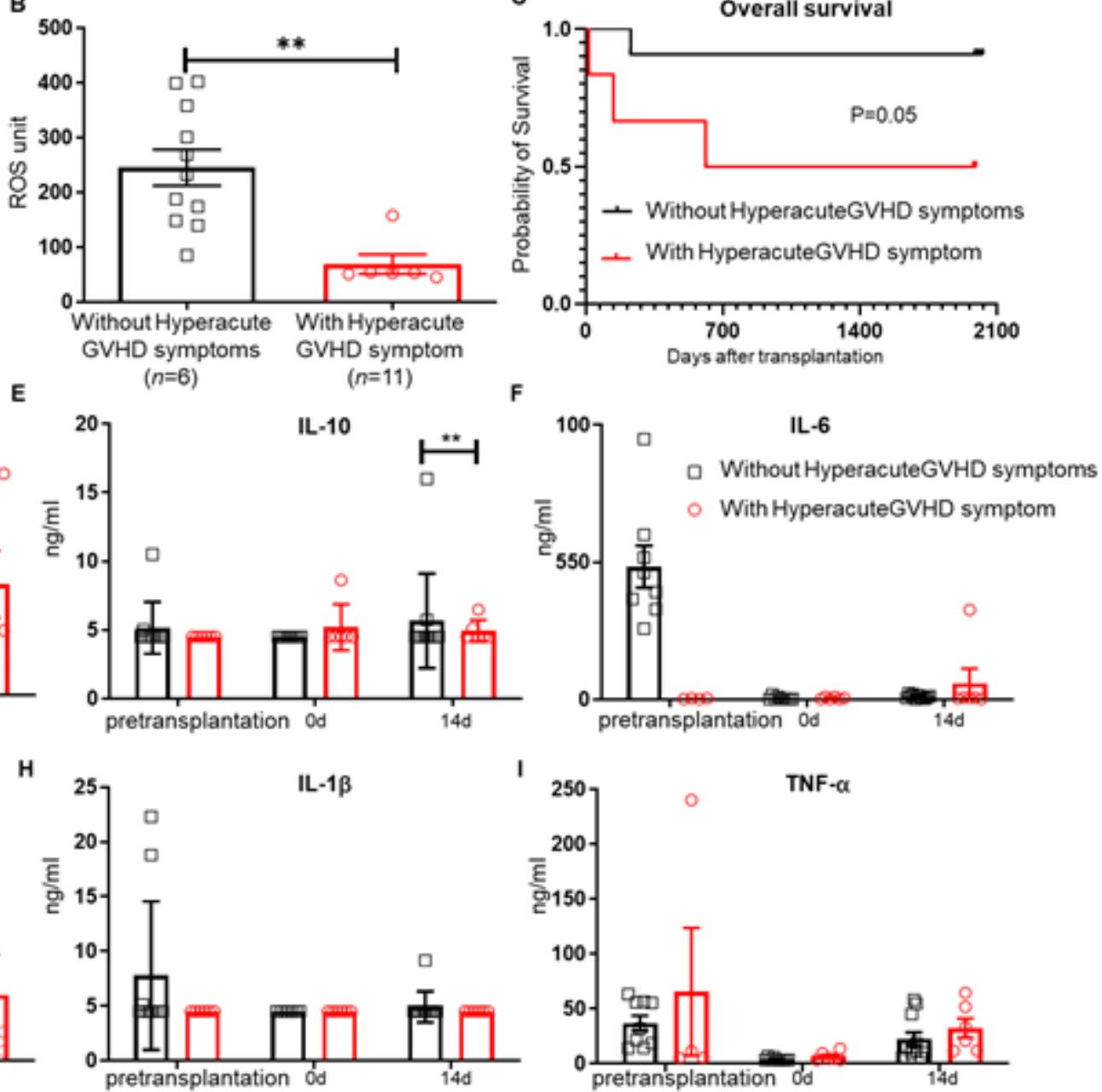

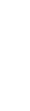

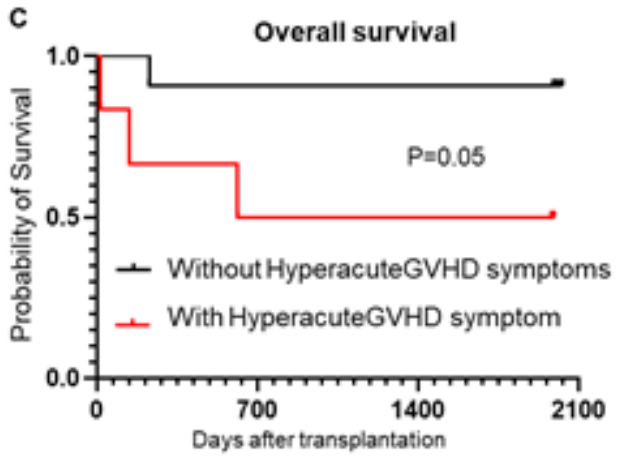

IL-6

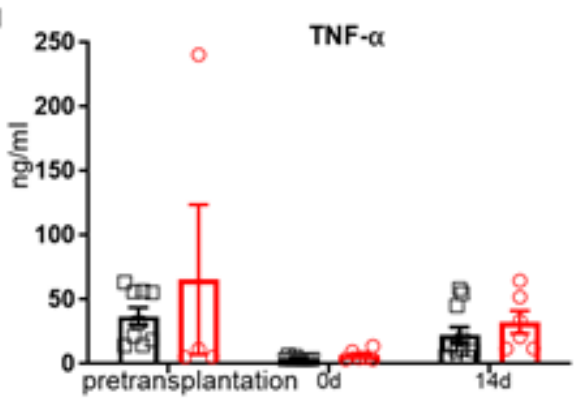

Figure 2

Patients with low ROS level before transplantation are more likely to have hyperacute GVHD symptoms after transplantation. (A) Scheme of the experimental design. (B) The level of ROS in the peripheral blood of patients with or without hyperacute GVHD symptoms on the day of allo-HSCT, before donor stem cells were infused, using the Amplex Red assay. (B) Overall survival of different group. (D-I) Cytokines of serum from each group. Individual values are shown on graphs. ${ }^{*}<<0.05 ; * * 0<01$. 

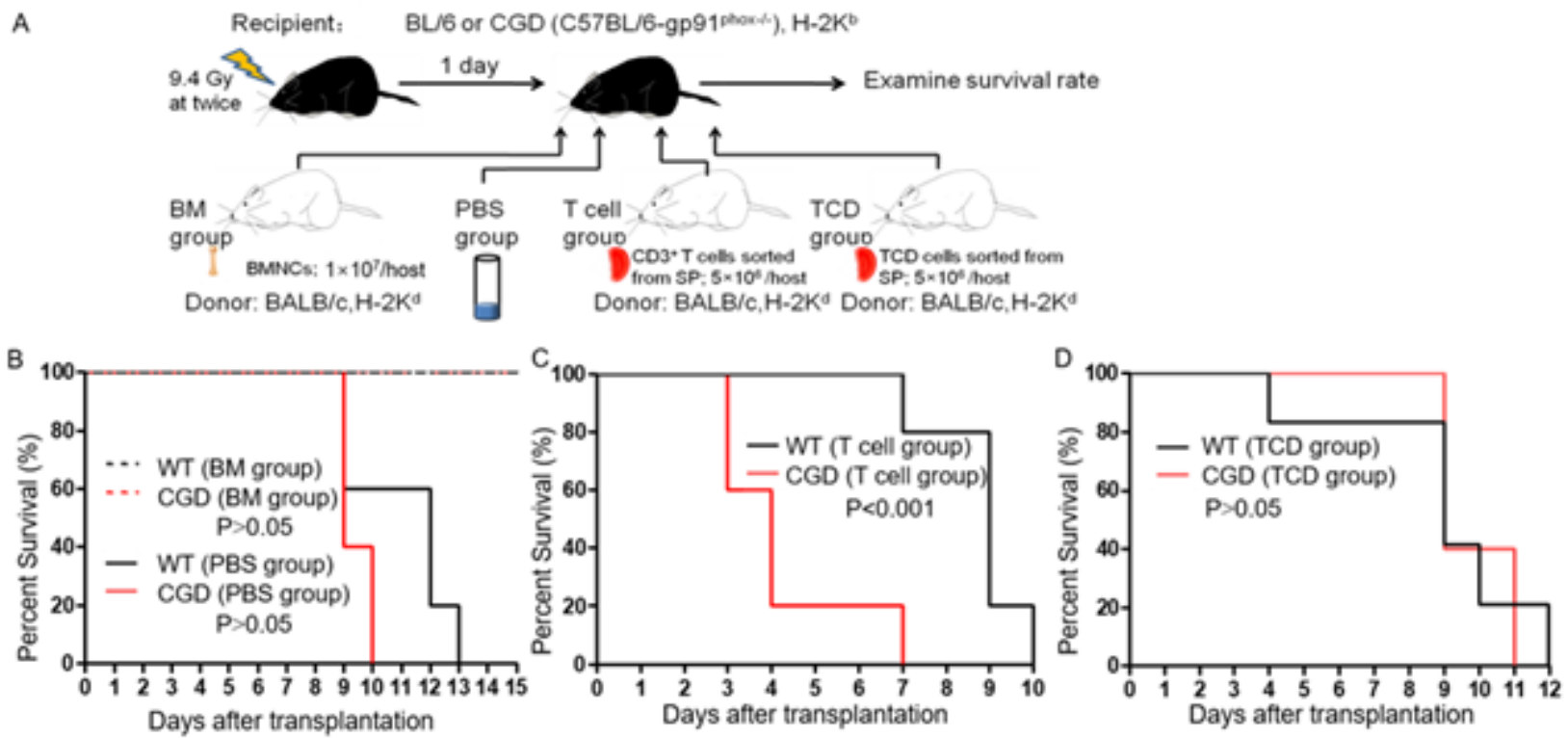

Figure 3

Donor-derived splenic T cells account for Hyperacute GVHD. (A) Schematic representation of the experiments of different components of allogeneic cell transplantation. Lethal irradiated CGD or WT mice of BM group received $1 \times 10^{7}$ donor bone marrow cells on the day of transplantation. The mice of the PBS group did not receive any cells but only 400ul PBS during transplantation. The mice of the T cell group received $5 \times 10^{6} \mathrm{CD}^{+} \mathrm{T}$ cells sorted from spleens of donors (BALB/c mice) by the use of MACS, and the mice of the $T$ cell depleted (TCD) group received $5 \times 10^{6}$ depleted $C D 3^{+} T$ cells sorted from donor spleens cells. (B) All CGD and WT mice of BM groups survived at the end of observation (day 40). There was no significant difference in cumulative survival rates between CGD and WT mice of the PBS group. (C) CGD mice of the T cell group had significantly shorter survival than WT mice $(P<0.001)$. (D) Survival curves of CGD and WT mice of the TCD group were nearly identical. These results are representative of at least 3 independent experiments ( $n=5$ for each group). 

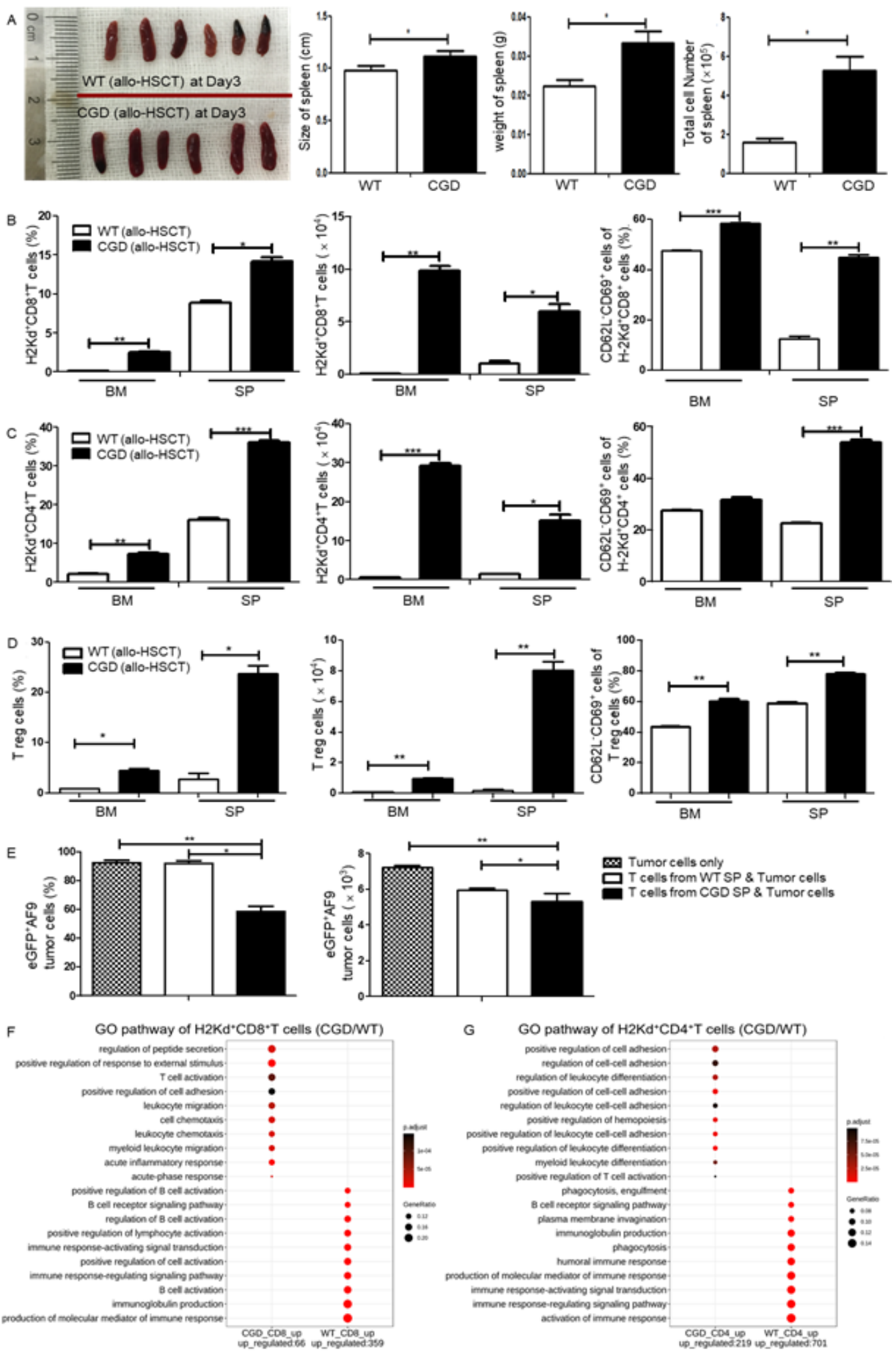

Figure 4

Elevated activity of allo-reactive T cells during hyperacute GVHD. WT and CGD mice were sacrificed when CGD mice suffered from hyperacute GVHD (at day 3 after allo-HSCT). (A)The spleen of CGD mice was enlarged during hyperacute GVHD. The appearances; the sizes; the weight and the total cell number of each spleen of the CGD and WT mice. (B-D) The frequencies, absolute number and the percentage of activated donor-derived $\left(\mathrm{H}-2 \mathrm{~K}^{\mathrm{d}+}\right) \mathrm{CD} 8^{+} \mathrm{T}, \mathrm{CD} 4^{+} \mathrm{T}$ cells and regular $\mathrm{T}$ cells $\left(\mathrm{CD} 4^{+} \mathrm{CD} 25^{+} \mathrm{FOXP3}{ }^{+} \mathrm{T}\right.$ cells, $\mathrm{T}$ 
reg cells) in the BM and spleen of WT mice and CGD mice were measured. (E) $\mathrm{H}-2 \mathrm{~K}^{\mathrm{d}+} \mathrm{CD}^{+} \mathrm{T}$ cells sorted from spleen of CGD or WT mice that received allo-HSCT 3 days earlier were cocultured with $\mathrm{H}_{2} \mathrm{~Kb}^{+} \mathrm{eGFP}^{+} \mathrm{AF} 9$ tumor cells for 18 hours in the live cell station. The frequencies and absolute number of tumor cells at the end of observation. Dot graph shows GO pathways up and down regulated in $\mathrm{H} 2 \mathrm{Kd}^{+} \mathrm{CD} 8^{+} \mathrm{T}$ cells $(\mathrm{F})$ and $\mathrm{H} 2 \mathrm{Kd}^{+} \mathrm{CD} 4^{+} \mathrm{T}$ cells $(\mathrm{G})$ sorted from spleen of CGD or WT mice at day 3 after allo-HSCT. Dot size relates to the number of differentially expressed genes. Data are expressed as mean \pm standard error (SE). ${ }^{*} P<0.05 ; * \star P<0.01$, ${ }^{\star \star \star} P<0.001$. Gene sets were considered statistically significant at $\mathrm{P}$-value $<0 \cdot 05$. These results are representative of at least 3 independent experiments with greater than 5 mice in each group. 

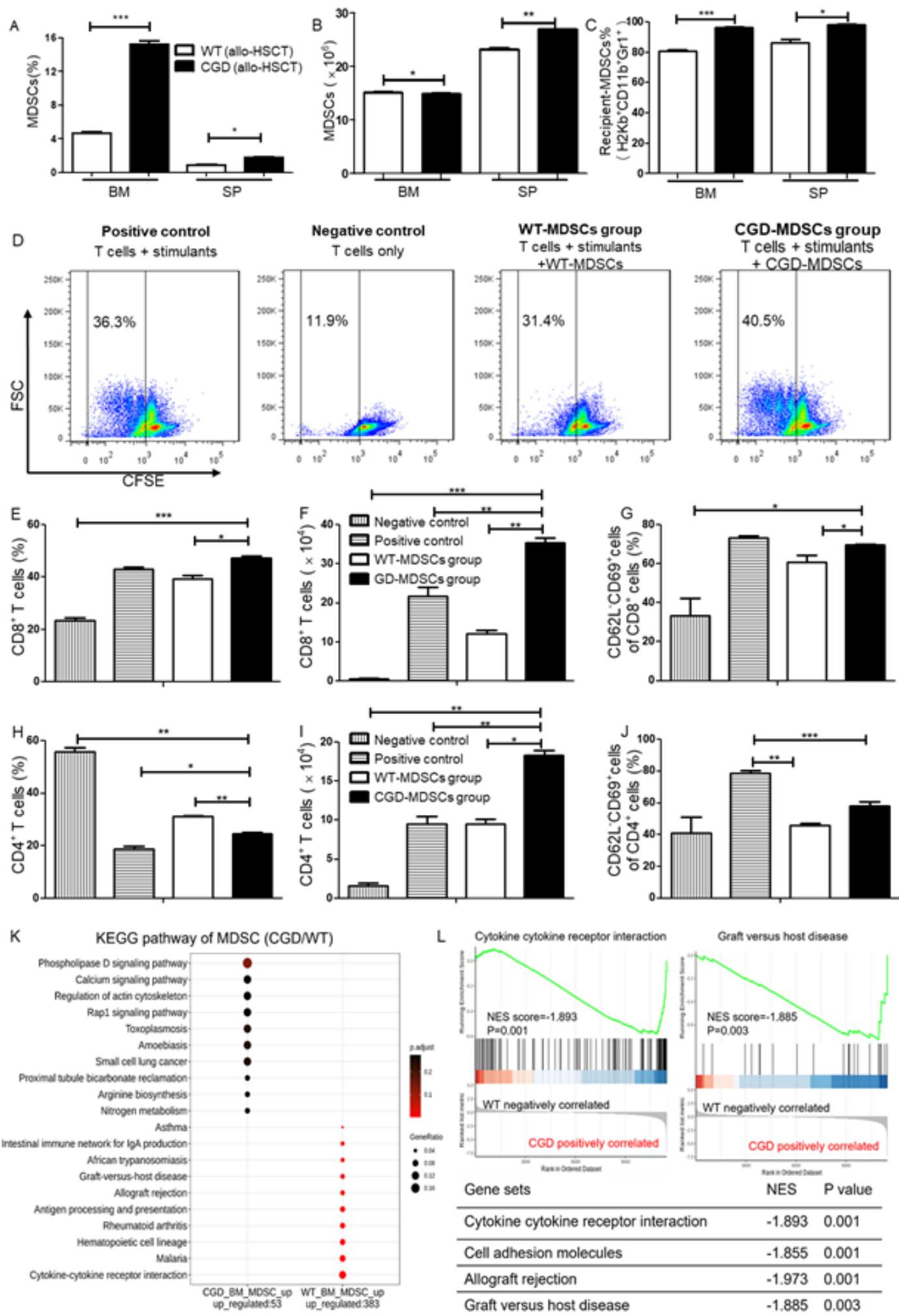

Figure 5

MDSCs with ROS deficiency were unable to suppress T cell immune responses.

A) The frequencies, B) the absolute number and $C$ ) the percentage of recipient-derived MDSCs $\left(\mathrm{CD} 11 \mathrm{~b}^{+} \mathrm{Gr}^{+}\right)$in the spleen of WT mice and CGD mice were measured during hyperacute GVHD (at day 3 after allo-HSCT). Recipient-derived MDSCs $\left(\mathrm{H}-2 \mathrm{~K}^{\mathrm{b}+} \mathrm{CD} 11 \mathrm{~b}^{+} \mathrm{GR} 1^{+}\right.$cells) were sorted from BM cells of 
recipient WT or CGD mice at day 3 after allo-HSCT using a BD FACS Aria III flow sorter. T cells obtained from spleen of normal mice using CD3 positive bead selection were stimulated with anti-CD3, anti-CD28 antibody and IL-2 for 3 days (positive control), with or without the addition of MDSCs sorted from BM of WT mice (WT-MDSCs group), or from BM of CGD mice (CGD-MDSCs group). Negative control consisted of $\mathrm{CD}^{+} \mathrm{T}$ cells only. CFSE proliferation profiles were analyzed with flow cytometry (D). The frequencies and absolute number of $\mathrm{CD} 8^{+} \mathrm{T}$ cells and $\mathrm{CD} 4^{+} \mathrm{T}$ cells in all $\mathrm{T}$ cells (E,F, $\mathrm{H}$ and $\mathrm{I}$, respectively). The percentage of activated $\mathrm{CD} 8^{+} \mathrm{T}$ cells and $\mathrm{CD} 4^{+} \mathrm{T}$ cells $\left(\mathrm{CD} 62 \mathrm{I}^{-} \mathrm{CD} 69^{+}\right)$were measured $(\mathrm{G}, \mathrm{J})$. (K) Dot graph shows KEGG pathways up and down regulated in recipient-derived MDSCs sorted from BM of CGD or WT mice at day 3 after allo-HSCT. Dot size relates to the number of differentially expressed genes. (L) Gene pathways that were differentially expressed in CGD-MDSCs and WT-MDSCs according to GSEA. Data are expressed as mean \pm standard error (SE). ${ }^{*} P<0.05 ;{ }^{* \star} P<0.01 ;{ }^{* \star *} P<0.001$. These results are representative of at least 3 independent experiments. Gene sets were considered statistically significant at $P$-value $<0.05$. These results are representative of at least 3 independent experiments with greater than 5 mice in each group. Data were analysed with R3.3.5 software and GSEA. 
A

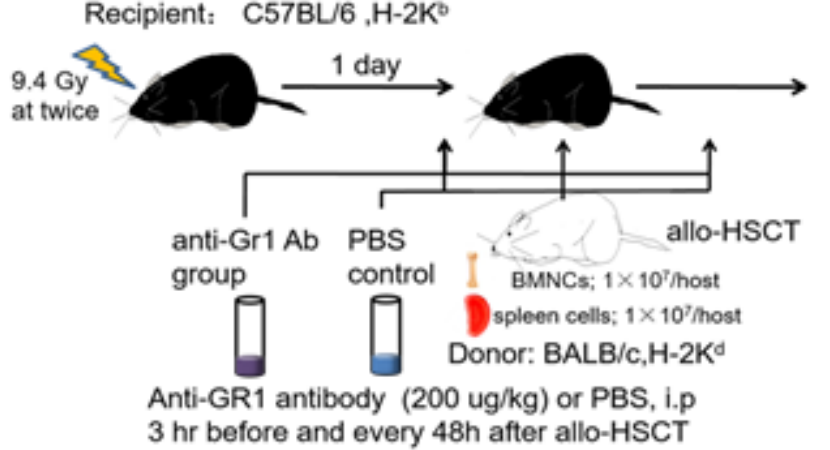

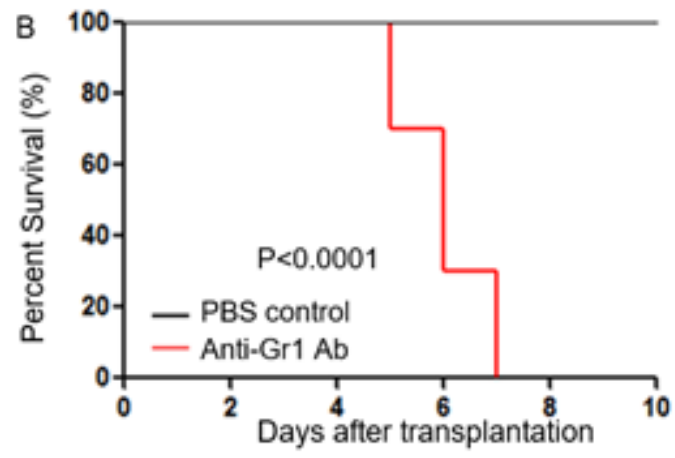

C
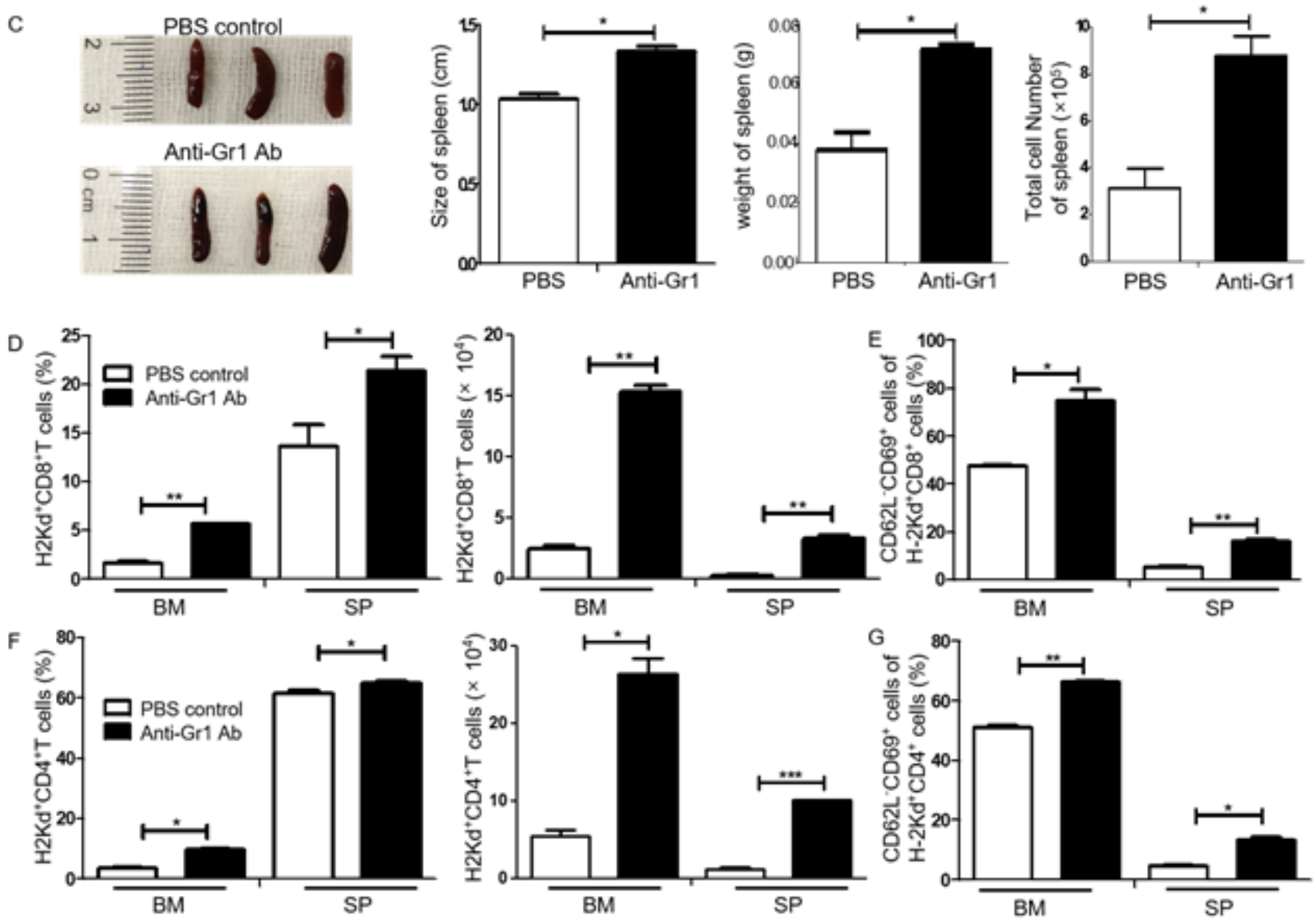

Figure 6

WT mice develop hyperacute GVHD with MDSCs depletion. (A) Schematic representation of the experimental procedure. Lethally irradiated WT $\left(\mathrm{H}-2 \mathrm{~K}^{\mathrm{b}}\right)$ mice were injected intravenously on day 0 with BM cells and spleen cells of age- and gender-matched BALB/c $\left(\mathrm{H}-2 \mathrm{~K}^{\mathrm{d}}\right)$ mice. WT Mice in anti-Gr1Ab group were injected intraperitoneally with anti-Gr1Ab $(200 \mathrm{ug} / \mathrm{kg})$ in PBS 3 hours before and every $48 \mathrm{~h}$ after alloHSCT to deplete MDSCs, while WT Mice in PBS control group were treated with the same volume of PBS at each time point. WT mice in anti-Gr1Ab group had significantly shorter survival (B). (C) The appearances, the sizes, the weight and the total cell number of each spleen of the WT mice of two groups after allo-HSCT at day5. The activity of alloreactive T cells was elevated after intraperitoneal injecting anti-Gr1Ab. The frequencies and absolute number of donor-derived $\left(\mathrm{H}-2 \mathrm{~K}^{\mathrm{d}+}\right) \mathrm{CD} 8^{+} \mathrm{T}$ cells $(\mathrm{D})$ and $\mathrm{CD} 4^{+} \mathrm{T}$ cells (F) in the BM and spleen of WT mice in the anti-Gr1Ab group and in the PBS control group were 
measured at day 5 after allo-HSCT. The percentage of CD62 $\mathrm{L}^{-} \mathrm{CD} 69^{+} \mathrm{H}-2 \mathrm{~K}^{\mathrm{d}+} \mathrm{CD} 8^{+}$and $\mathrm{CD} 4^{+} \mathrm{T}$ cells in the BM and spleen of WT mice in anti-Gr1Ab group were significantly higher than that of control group (E and G). Data are expressed as mean \pm standard error (SE). ${ }^{*} P<0.05 ; * \star P<0.01,{ }^{\star * \star} P<0.001$. These results are representative of at least 3 independent experiments.

A Recipient: CGD (C57BL/6-gp91 ${ }^{\text {phox-/ }), ~ H-2 K^{\circ}}$

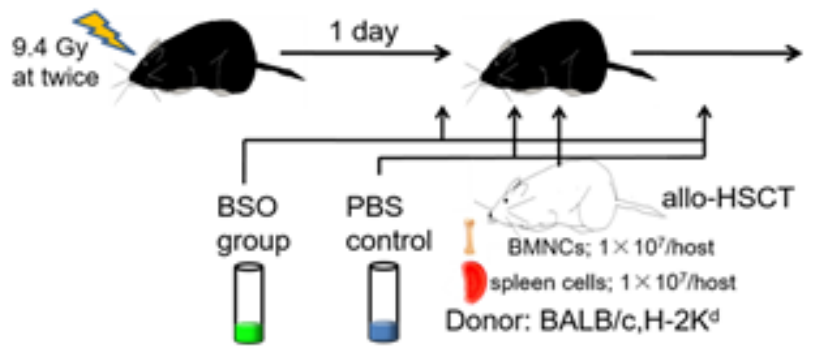

BSO (10 mg/kg) or PBS, i.p

$3 \mathrm{hr}$ before and every morning after allo-HSCT

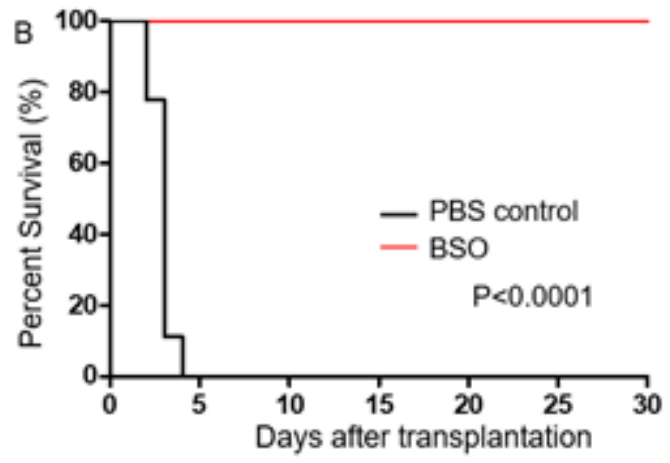

C
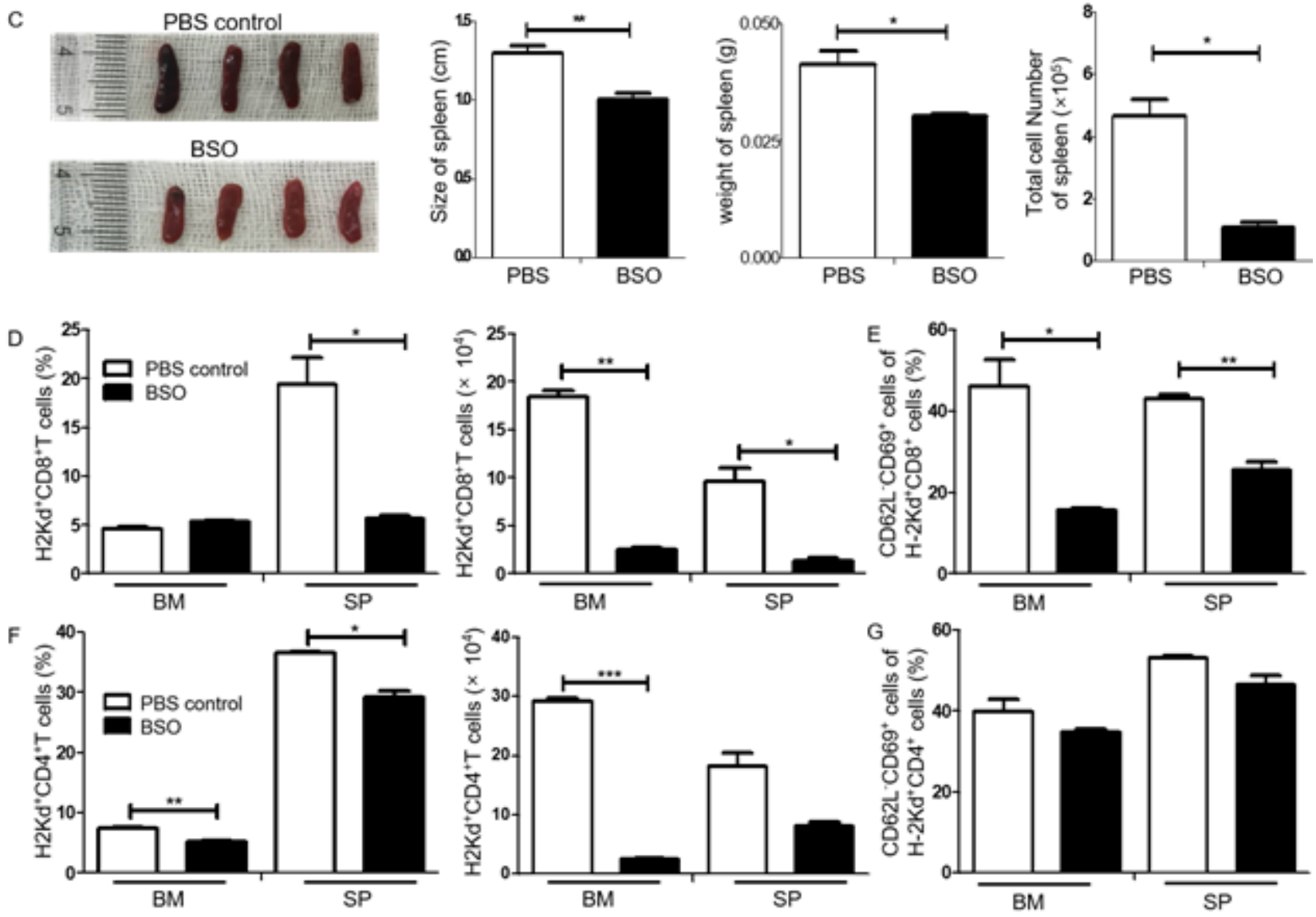

Figure 7

ROS agonist rescues the hyperacute GVHD phenotype of CGD mice. (A) Schematic representation of the experimental procedure. Lethally irradiated CGD (gp91 ${ }^{\text {phox } /-}, \mathrm{H}-2 \mathrm{~K}^{\mathrm{b}}$ ) mice were injected intravenously on day 0 with BM cells and spleen cells of age- and gender-matched BALB/c $\left(H-2 K^{d}\right)$ mice. CGD mice in the BSO group were treated with BSO (10 mg/kg, i.p.) $3 \mathrm{hr}$ before and every morning after allo-HSCT, while CGD mice in the control group were treated with the same volume of deionized water at each interval. CGD mice treated with BSO had significantly longer survival (B). (C)The appearances, the sizes, the 
weight and the total cell number of each spleen of the CGD mice of two groups after allo-HSCT at day3 are shown. The activity of alloreactive $T$ cells decreased after intraperitoneal injecting BSO. The frequencies and absolute number of donor-derived $\left(\mathrm{H}-2 \mathrm{~K}^{\mathrm{d}+}\right) \mathrm{CD} 8^{+} T$ cells and $\mathrm{CD} 4^{+} T$ cells $(D, F)$ in the $B M$ and SP of CGD mice in BSO group and in PBS control group were measured at day 3 after allo-HSCT. The levels of CD69 and CD62L were analyzed with flow cytometry for CD8 ${ }^{+} T$ cells and $C D 4^{+} T$ cells (E and $G$ ) of BM and spleen of CGD mice rescued by BSO or not rescued at day 3 after allo-HSCT. Data are expressed as mean \pm standard error (SE). ${ }^{\star} P<0.05 ; * * P<0.01$, ${ }^{\star \star \star} P<0.001$. These results are representative of at least 3 independent experiments.
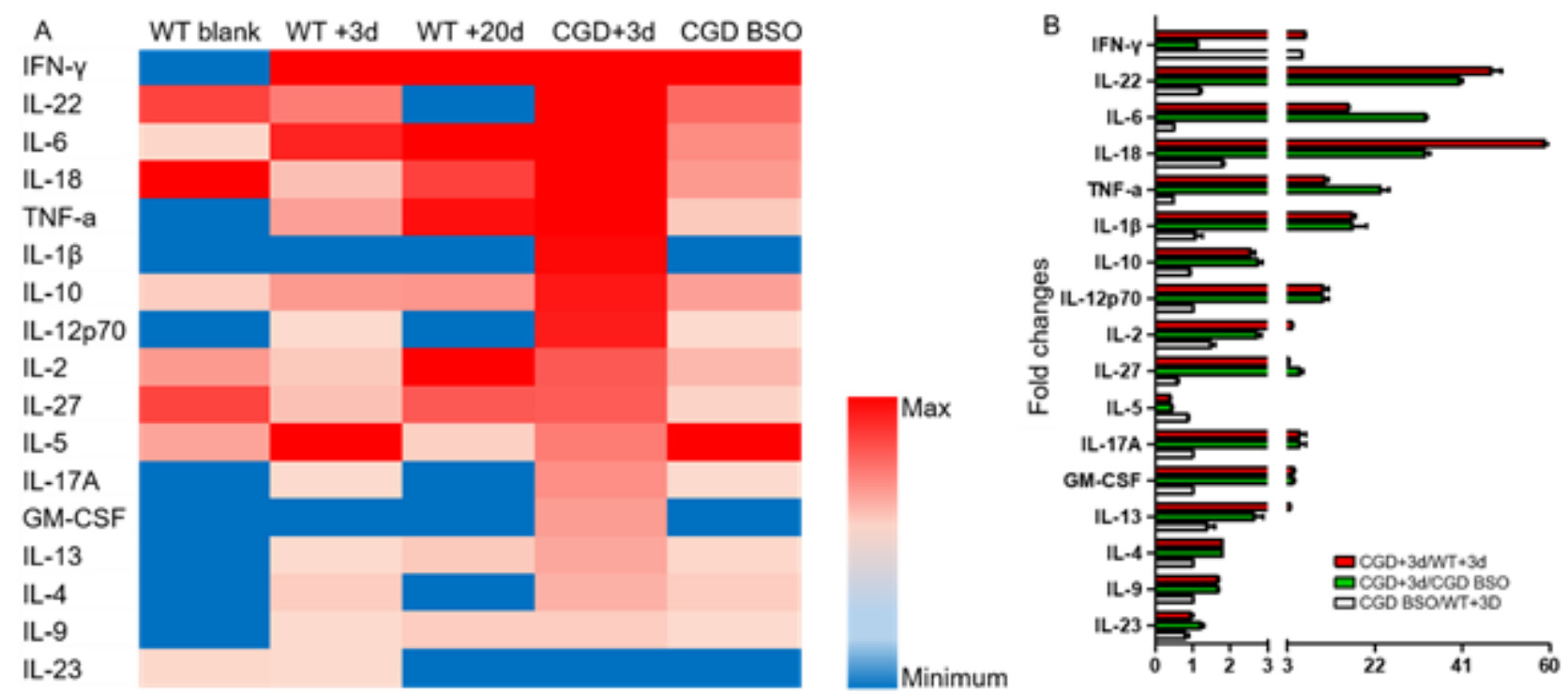

$\mathrm{C}$

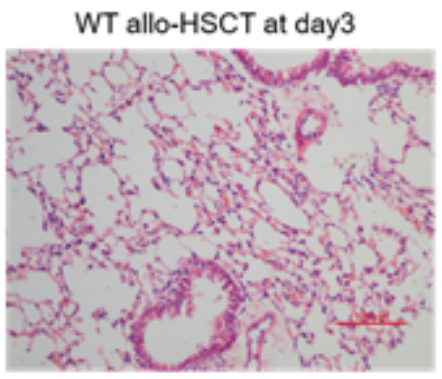

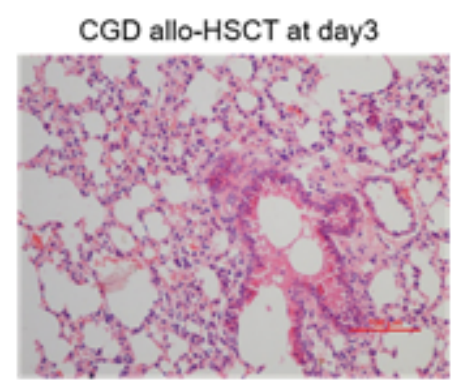

D

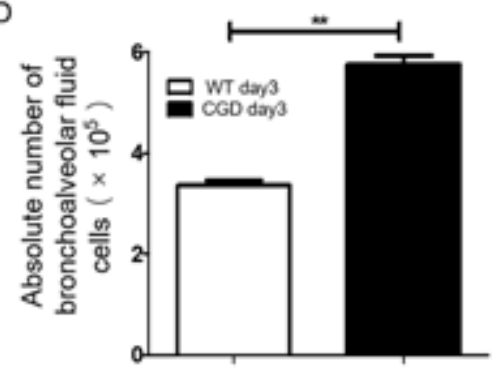

Figure 8

Cytokine Release Syndrome might cause the death of CGD mice suffering hyperacute GVHD. WT and CGD mice treated with or without BSO were sacrificed at day 3 after allo-HSCT. Cytokine profiles (A) and the fold of changes $(B)$ of serum from each group were compared with cytokine arrays as described (ProcartaPlex Analyst 1.0, USA, ebioscience company). Histological changes of the lung (G) and nucleated cells content in bronchoalveolar fluid $(\mathrm{H})$ of WT and CGD mice after allo-HSCT at day 3.

\section{Supplementary Files}

This is a list of supplementary files associated with this preprint. Click to download. 
- SupplementaryVideo2wt.avi

- SupplementaryVideo1CGD.avi

- supplementFigure.docx 